\title{
Shakespeare dans Candy : mais est-ce vraiment pour les enfants?
}

Sarah Hatchuel et Ronan Ludot-Vlasak

\section{Q OpenEdition \\ 1 Journals}

\section{Édition électronique}

URL : https://journals.openedition.org/shakespeare/3632

DOI : 10.4000/shakespeare.3632

ISSN : 2271-6424

Éditeur

Société Française Shakespeare

\section{Référence électronique}

Sarah Hatchuel et Ronan Ludot-Vlasak, « Shakespeare dans Candy : mais est-ce vraiment pour les enfants? », Actes des congrès de la Société française Shakespeare [En ligne], 34 | 2016, mis en ligne le 10 mars 2016, consulté le 06 juillet 2021. URL : http://journals.openedition.org/shakespeare/3632 ; DOI : https://doi.org/10.4000/shakespeare.3632

Ce document a été généré automatiquement le 6 juillet 2021.

(c) SFS 


\title{
Shakespeare dans Candy: mais est- ce vraiment pour les enfants?
}

\author{
Sarah Hatchuel et Ronan Ludot-Vlasak
}

1 Candy, manga japonais en neuf volumes de Yumiko Igarashi (dessinatrice) et Kyoko Mizuki (scénariste), a été adapté en une série télévisée d'animation (ou anime) pour enfants comprenant 115 épisodes de 26 minutes diffusés entre 1976 et 1979 (à partir de septembre 1978 en France) ${ }^{1}$. Son intrigue suit les épreuves d'une jeune fille orpheline américaine de l'enfance à l'âge adulte. À la veille de la Première Guerre mondiale, Candy est adoptée par une famille de la grande bourgeoisie, stricte et souvent cruelle. Lorsqu'Anthony, son premier amour, meurt des suites d'un accident de cheval, elle est envoyée en pension dans un sévère collège londonien. Elle y tombe sous le charme du ténébreux Terrence (Terry) Grandchester, fils illégitime d'un duc anglais et d'une roturière américaine, grande actrice à Broadway. Pour que Candy ne soit pas renvoyée $\mathrm{du}$ collège, Terry repart en Amérique où il tente sa chance comme acteur shakespearien.

2 Alors que les adaptations de Shakespeare à l'écran sont en jachère à cette période et que les Animated Tales ${ }^{2}$ n'existent pas encore, Candy, anime qui a été d'abord diffusé au Japon puis exporté dans de très nombreux pays (France, Espagne, Italie, Suisse, Grèce, Turquie, mais aussi Suède, Pologne, Yougoslavie, Maroc, Tunisie, Algérie, Chine et dans toute l'Amérique Latine), a fait découvrir Shakespeare à toute une génération d'enfants nés dans les années 1970 en leur donnant l'occasion d'assister à des scènes (certes fragmentées et parfois traduites approximativement) tirées de Macbeth, du Roi Lear et de Roméo et Juliette. Si l'on suit à la lettre le générique français du feuilleton, qui nous rappelle que le monde de l'héroïne est peuplé de "méchants » et de "gentils ${ }^{3}$ ", on serait tenté de voir dans les usages shakespeariens qui s'y manifestent de simples échos mièvres dépourvus de toute ambivalence. Or bien que l'anime n'échappe pas aux clichés et aux facilités mélodramatiques, il est étonnant de voir une fiction non anglophone pour la jeunesse tenir un discours aussi complexe sur les transactions angloaméricaines de Shakespeare. Dans un contexte géopolitique où le Japon est sous influence américaine dans les années 1970, le capital culturel ${ }^{4}$ de Shakespeare et la 
figure canonique qu'il représente sont sources d'ambivalences et d'hybridations aussi bien idéologiques que génériques ou esthétiques. Il s'agira ainsi d'explorer les lignes de faille d'un feuilleton qui construit une tension entre un shakespeare " authentiquement » britannique ${ }^{5}$ et un Shakespeare américain populaire ${ }^{6}$, met au jour les mécanismes mêmes de la production théâtrale et interroge sa portée au sein de la société.

3 L'intrigue de Candy repose d'emblée sur un jeu de va-et-vient transatlantiques entre les États-Unis et le Royaume-Uni. L'héroïne grandit près du lac Michigan (voir illustration 1) où l'atmosphère bucolique rappelle la vision pastorale d'un Thomas Jefferson qui prône le développement d'une nation agricole libérée des vices urbains et instaure une tradition culturelle solidement ancrée dans l'imaginaire américain du long XIX ${ }^{\mathrm{e}}$ siècle ${ }^{7}$.

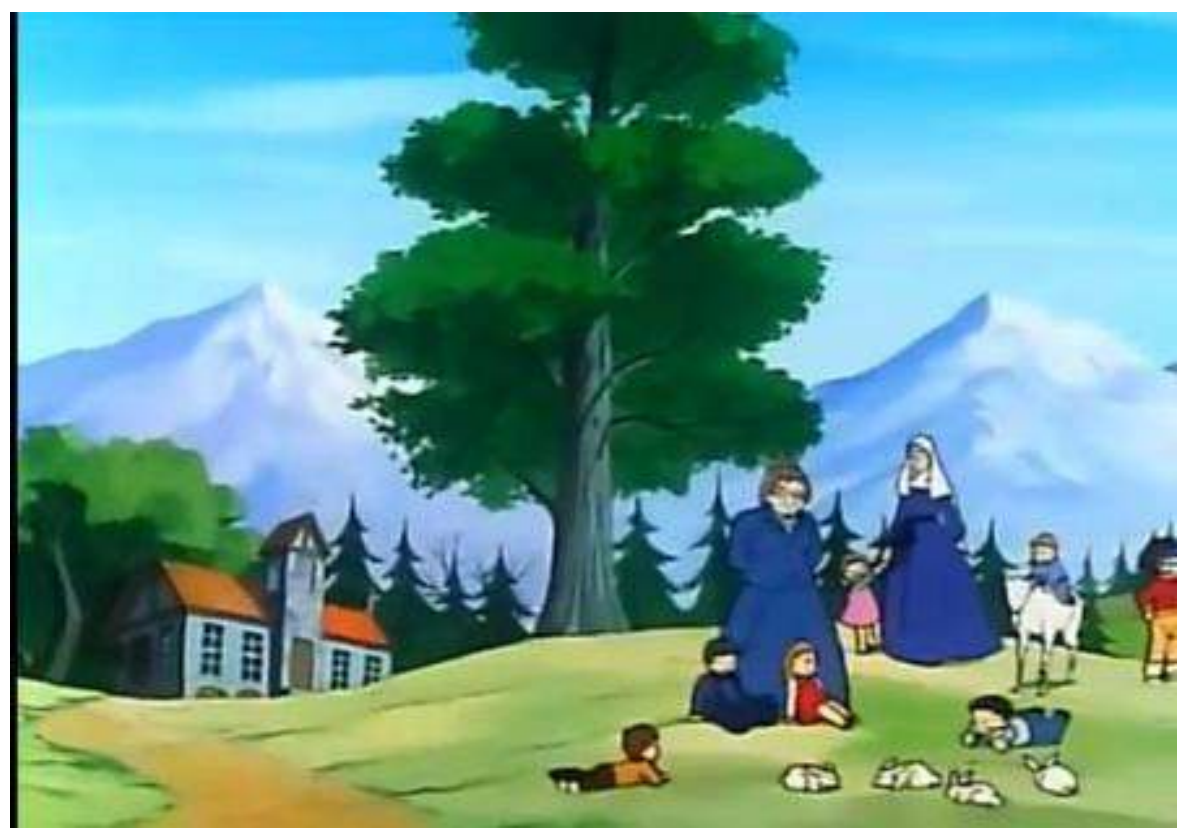

Illustration 1 : L'atmosphère bucolique américaine dans Candy, capture d'écran de l'épisode 34.

Archive personnelle

TOEI Animation Co., Ltd. Tous droits réservés

4 Candy est par la suite envoyée dans un pensionnat anglais - le Collège Royal de Saint Paul. Après une année passée dans cet établissement des plus traditionnaliste, qui éduque des héritiers et héritières issus de lignées prestigieuses, elle fugue et retourne en Amérique. Les autres personnages qui accompagnent l'existence de l'héroïne - ses ennemis Daniel et Eliza Legrand, ses amis Archibald et Alistair André, ainsi qu'Annie, avec qui elle fut élevée dans l'orphelinat de Mademoiselle Pony - suivent les mêmes trajectoires en étudiant, eux aussi, à Londres avant de rentrer en Amérique lorsque la Première Guerre mondiale éclate. Tandis que les villes américaines sont dépeintes en termes de mouvement et d'énergie, telles un champ des possibles où tout individu est en mesure d'accomplir ce qu'il souhaite à force de volonté et d'effort, les premières images de Londres sont celles d'un monde minéral, vide et figé dont l'austérité est renforcée par les lignes droites du dessin et l'emploi de couleurs froides (voir illustration 2). Le collège de Saint Paul a tout d'une prison dont la façade est aussi sévère que ses couloirs sont lugubres (voir illustration 3). Cette immobilité est à l'image 
du poids des traditions - et surtout de l'hérédité - qui régit l'Angleterre telle qu'elle est dépeinte dans l'anime.

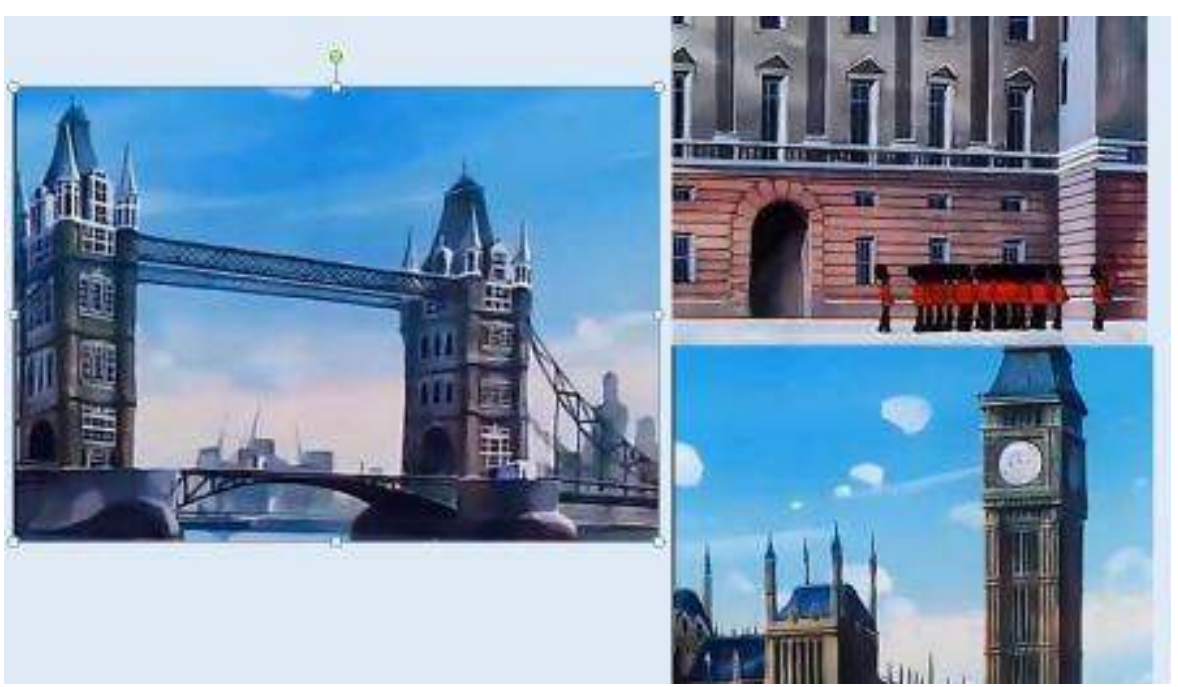

Illustration 2 : Londres comme monde minéral dans Candy, captures d'écran de l'épisode 31.

Archive personnelle.

TOEI Animation Co., Ltd. Tous droits réservés.

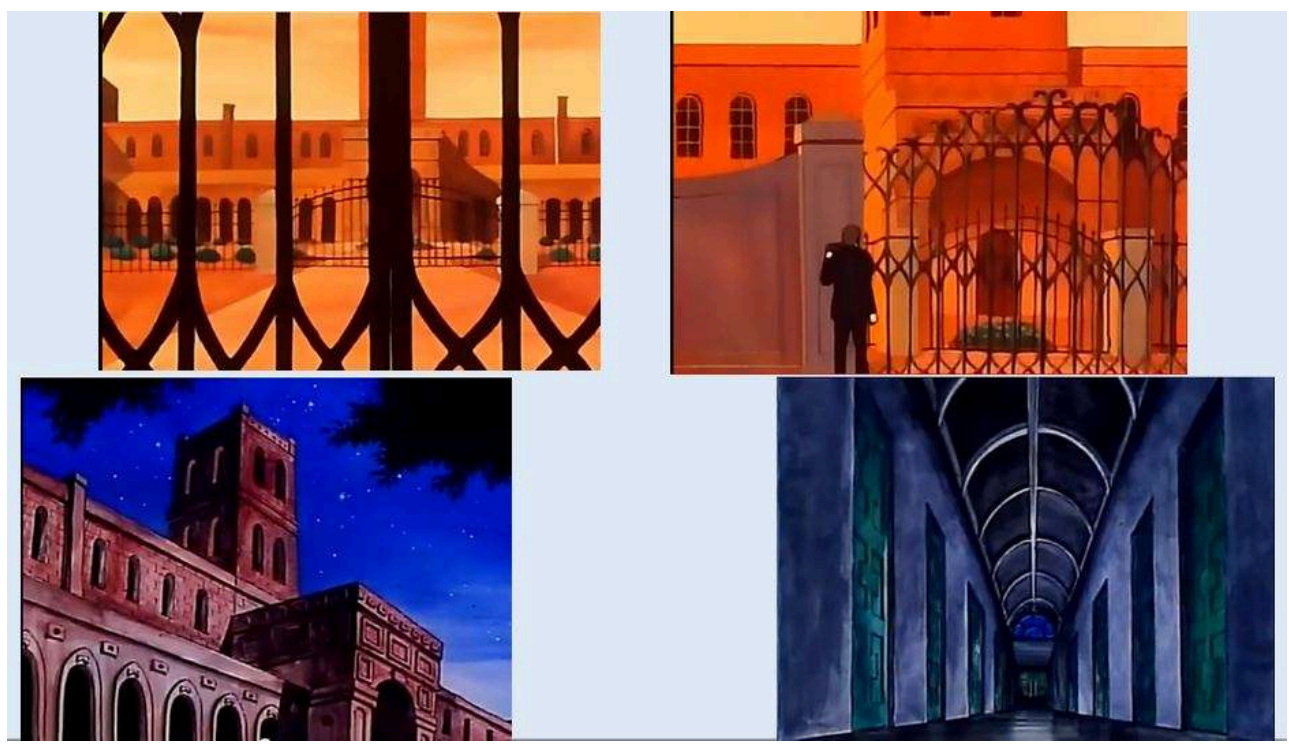

Illustration 3 : Le collège de Saint Paul comme prison, captures d'écran des épisodes 31 et 32.

Archive personnelle.

TOEI Animation Co., Ltd. Tous droits réservés.

Dans ce contexte d'opposition entre l'Ancien et le Nouveau Monde, Shakespeare sert de pont entre les cultures mais cristallise aussi leurs différences. Le Nouveau Monde porte les traces de la culture dramatique élisabéthaine. Un premier clin d'œil est le nom des chevaux des Legrand, César et Cléopâtre. Les façades de Broadway sont, quant à elles, couvertes d'affiches faisant la publicité de productions shakespeariennes (voir illustration 4); la troupe que Terry rejoint à New York se nomme Strasford et son directeur est un certain Hattaway - noms qui renvoient respectivement à la ville natale 
de Shakespeare et à celui de son épouse. L'actrice qui doit jouer Juliette aux côtés de Terry s'appelle Suzanne Marlowe: si son prénom rappelle celui de la fille aînée de Shakespeare (Susanna), son patronyme évoque une carrière sur le point de s'interrompre aussi soudainement que celle du dramaturge. Cependant, même si ses racines britanniques sont rappelées, Shakespeare se trouve américanisé. Les représentations n'ont, en effet, jamais lieu en Angleterre : c'est à Chicago et à New York que Terry joue et triomphe.

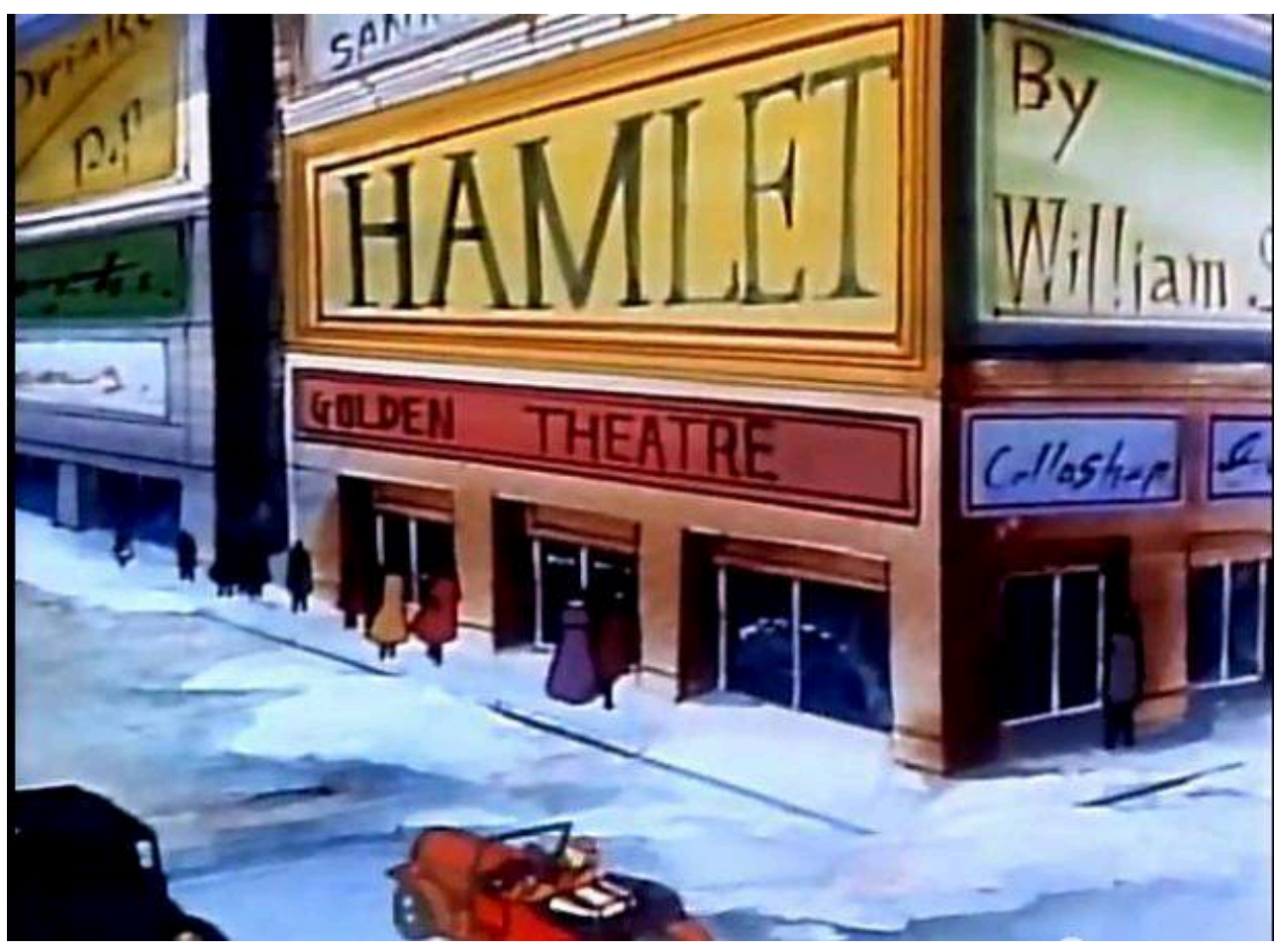

Illustration 4 : Les façades shakespeariennes de Broadway, capture d'écran de l'épisode 97.

Archive personnelle.

TOEI Animation Co., Ltd. Tous droits réservés.

Symboliquement, les spectateurs font la connaissance du futur acteur shakespearien, au milieu de l'Atlantique, à mi-chemin entre les deux cultures dont il incarne la rencontre et les tensions (voir illustration 5). 


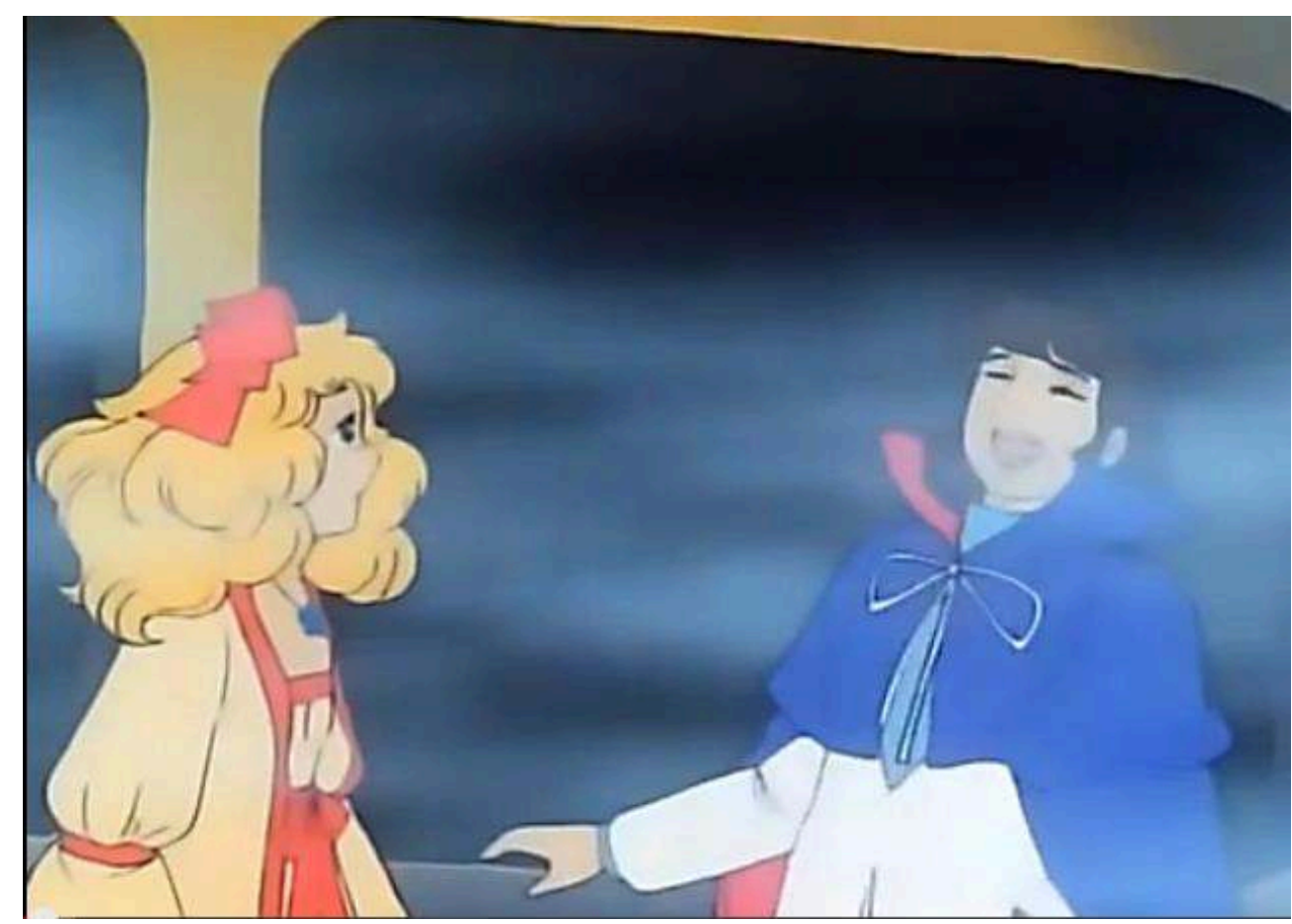

Illustration 5 : La rencontre de Candy et Terry sur un paquebot transatlantique, capture d'écran de l'épisode 31.

Archive personnelle.

TOEI Animation Co., Ltd. Tous droits réservés.

7 La filiation de Terrence est à l'image des hybridations transatlantiques et des accents mélodramatiques du feuilleton. Le jeune homme est le fruit des amours interdites entre une actrice américaine très populaire - Eléonore Baker - et un aristocrate anglais - le duc de Grandchester - qui avait préféré ne pas épouser une roturière indigne de son rang et avait emmené l'enfant en Angleterre pour le préparer à porter le titre. Terry a essayé de retrouver sa mère et lui a rendu visite à New York (c'est ce que l'on apprend en flashback dans l'épisode 38, "Le secret de Terry»), mais celle-ci ne l'accueille pas comme il l'aurait voulu. Son public ignore qu'elle a eu un fils naturel et elle entend protéger sa carrière. C'est au cours de son voyage de retour vers l'Angleterre que Terry croise le chemin de Candy pour la première fois.

8 S'il insulte volontiers l'Amérique en déclarant par exemple que «ses habitants sont tous des sauvages" (épisode 42), le jeune homme tourne finalement le dos à son héritage aristocratique et s'approprie les valeurs d'indépendance et de mobilité sociale célébrées en terre américaine : après avoir déclaré à son père qu'il ne « veu[t] pas $[\mathrm{s}] \mathrm{e}$ laisser ligoter par ces règles d'un autre temps » (épisode 46) et qu'il entend désormais ne compter que sur lui-même (épisode 49), il part à la conquête des théâtres de Broadway. Shakespeare apparaît ainsi au carrefour d'une tension entre, d'une part, l'héritage du passé et la filiation aristocratique et, d'autre part, la liberté de choisir son destin et de s'affranchir des diktats sociaux.

9 Refusant désormais de porter le nom prestigieux de la lignée à laquelle il appartient, Terry s'inscrit dans celle d'un Crèvecœur, qui souligne dans un passage célèbre que devenir américain est une renaissance défaisant les identités passées - Crèvecœur décide d'ailleurs de changer de prénom une fois installé en Amérique ${ }^{8}$. Bien que Terry 
rompe tout lien avec la branche anglaise de sa famille et devienne un modèle d'indépendance, ce renoncement au patronyme fait long feu. C'est bien sous le nom de Terrence Grandchester qu'il fait ses premiers pas sur la scène américaine comme s'il ne pouvait pas renoncer complètement à sa britannicité. Son prénom évoque d'ailleurs Ellen Terry, actrice anglaise à l'origine d'une véritable lignée théatrale (elle est la mère d'Edward Gordon Craig, la sœur de Fred Terry et la grand-tante de John Gielgud) ${ }^{9}$.

Dès son apparition dans le feuilleton, Terry est un personnage-histrion insaisissable, aux poses romantiques et torturées et aux multiples facettes, ce que le dessin souligne en le représentant souvent de manière kaléidoscopique (voir illustration 6). Il joue la comédie dans la vie (en faisant semblant de rire alors que Candy l'a vu pleurer ou en saluant ses interlocuteurs de manière théâtrale) et dénonce les traditions sociales et religieuses. La messe est ainsi, pour lui, une coutume hypocrite ${ }^{10}$. Adolescent rebelle, celui qui deviendra acteur lève ainsi le voile sur le théâtre qu'est la vie et parle de luimême à la troisième personne, de façon distanciée, pour construire un personnage défiant les règles: «Terrence Grandchester, héritier du titre, fume comme un sapeur, boit comme un Irlandais, se bat comme un chiffonnier, et se moque des règlements comme d'une guigne. S'il n'a pas encore été honteusement chassé du collège, c'est grâce aux dons que son père fait à la Supérieure ».

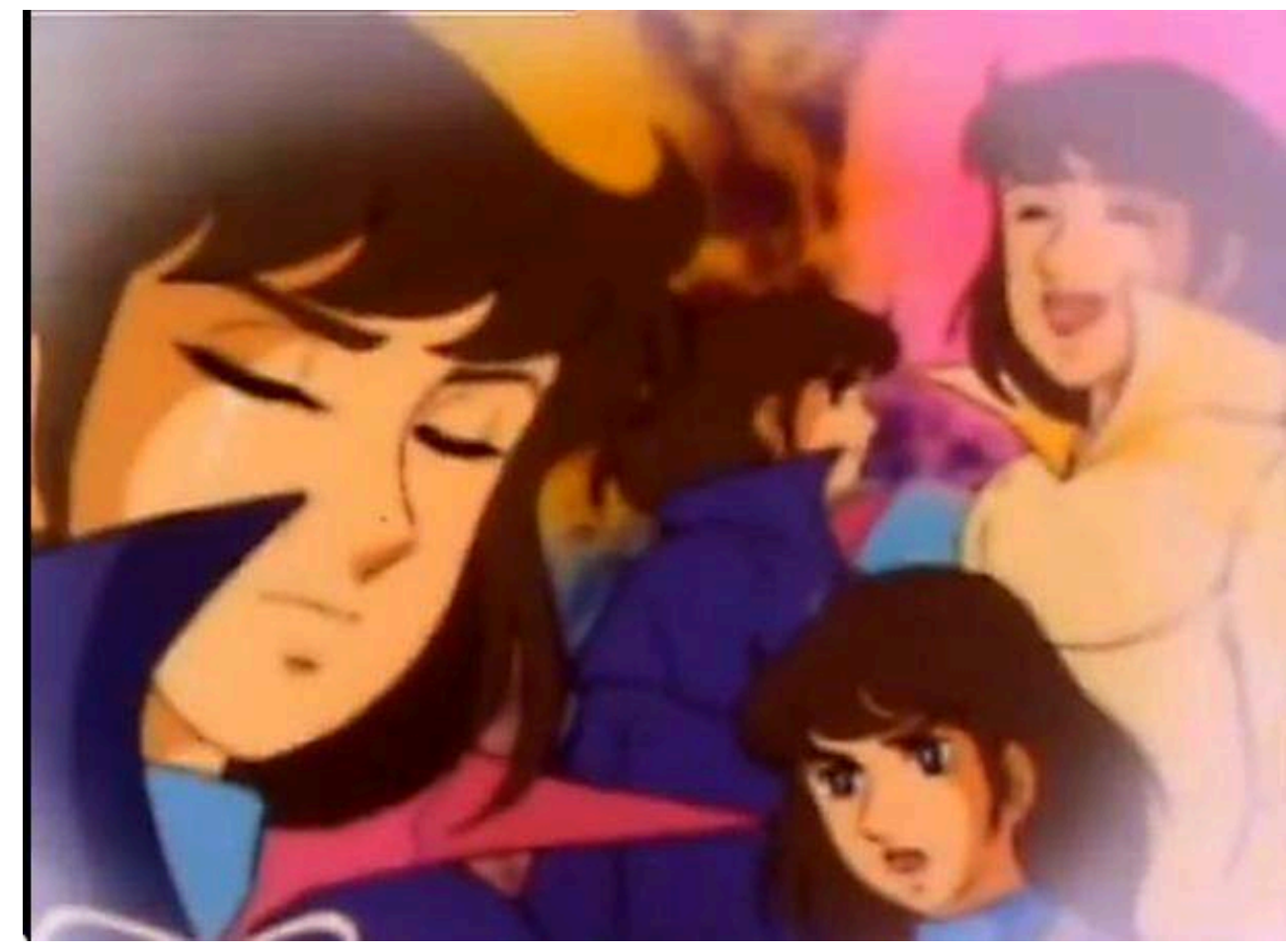

Illustration 6 : L'esthétique kaléidoscopique pour représenter Terry l'histrion, capture d'écran de l'épisode 38.

Archive personnelle

TOEI Animation Co., Ltd. Tous droits réservés.

11 Malgré son goût prononcé pour la transgression, c'est dans le répertoire canonique shakespearien qu'il va pourtant s'illustrer, fusionnant alors traditions britannique et américaine. Les représentations de Shakespeare dans Candy sont en effet filtrées par un jeu d'hybridations avec différents films shakespeariens ainsi qu'avec des œuvres 
américaines de la culture populaire. Dans ce faisceau d'allusions, se trouvent mêlés la période élisabéthaine, le début du XXe siècle et les années 1970.

La production de Macbeth dans laquelle joue Terry présente une affiche qui reprend de manière saisissante les traits, la coiffure et la couronne du roi dans le film de Roman Polanski, sorti en 1971 (voir illustration 7) ${ }^{11}$. De même, l'affiche de Roméo et Juliette évoque les costumes et les poses de l'adaptation réalisée par Franco Zeffirelli en 1968 (voir illustration 8). Ces allusions cinématographiques viennent troubler la temporalité $\mathrm{du}$ feuilleton, qui a pour cadre les deux premières décennies du $\mathrm{XX}^{\mathrm{e}}$ siècle, et brouillent les lignes de partage entre cultures savante et populaire.

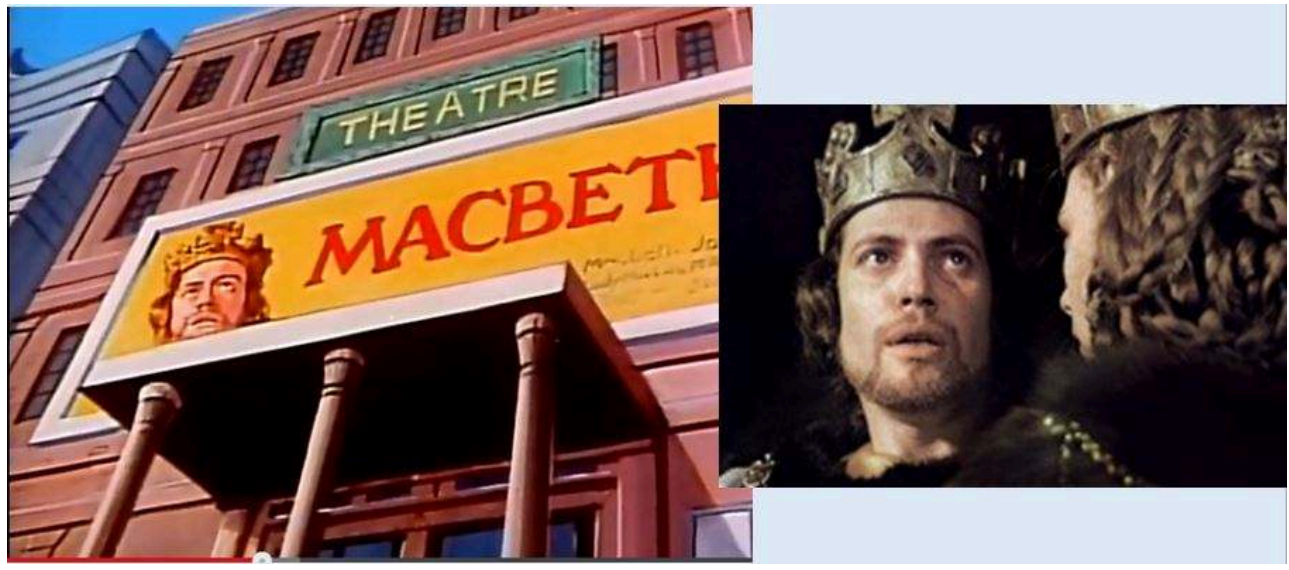

Illustration 7 : L'affiche de Macbeth dans Candy, capture d'écran de l'épisode 73, inspirée du film Macbeth de Roman Polanski (1971), personnages de Macbeth (John Finch) et Lady Macbeth (Francesca Annis, de dos) (capture d'écran, DVD, 2002).

Archive personnelle (Candy).

TOEl Animation Co., Ltd (Candy) / Columbia Distribution \& Sony Pictures Home Entertainment (Macbeth). Tous droits réservés.

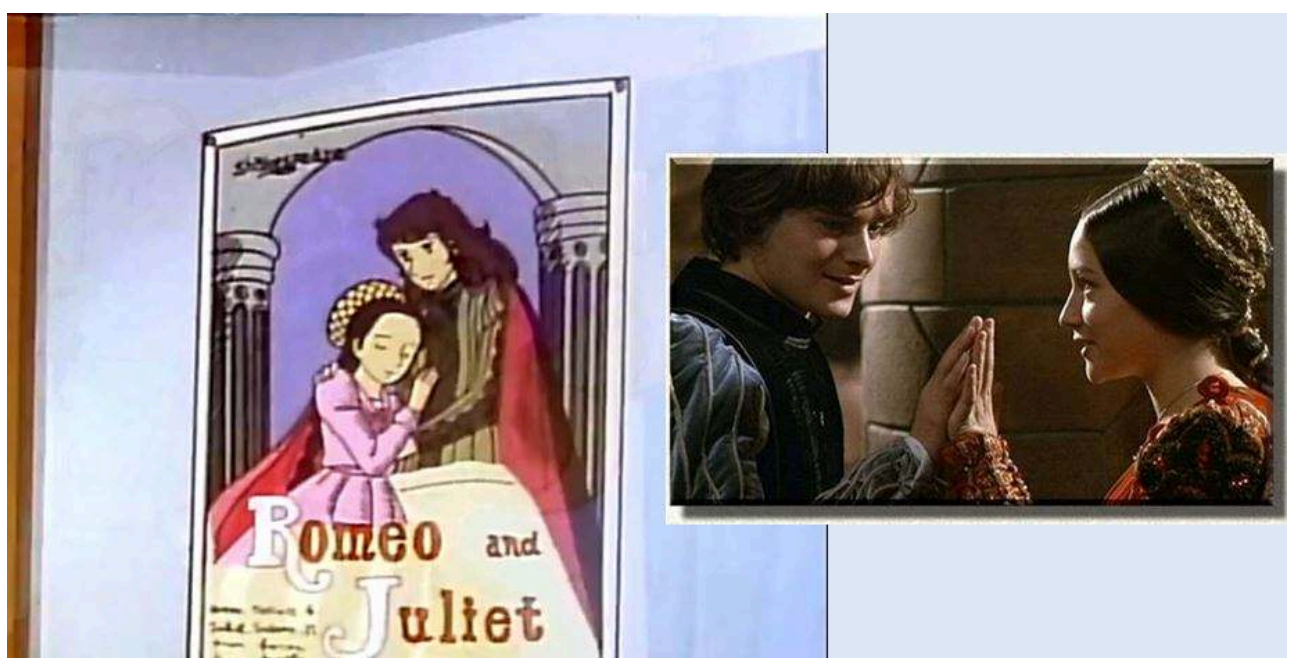

Illustration 8 : L'affiche de Roméo et Juliette dans Candy, capture d'écran de l'épisode 93, inspirée par le film Roméo et Juliette de Franco Zeffirelli (1968), personnages de Roméo (Leonard Whiting) et de Juliette (Olivia Hussey) (capture d'écran, DVD, 2003).

Archive personnelle (Candy)

TOEl Animation Co., Ltd (Candy) / Paramount Pictures (Romeo and Juliet). Tous droits réservés. 
D'autres échos du septième art contribuent, quant à eux, aux effets mélodramatiques qui imprègnent l'ensemble de l'anime. La scène d'adieu entre Terrence et Candy fait écho au célèbre escalier de la demeure de Scarlett O'Hara dans Autant en emporte le vent (réalisé par Victor Fleming en 1939), qui avait connu une nouvelle sortie mondiale en 1967, quelques années seulement avant la conception de Candy ${ }^{12}$ (voir illustration 9). Il est déjà fait allusion à ce classique du cinéma hollywoodien quelques épisodes plus tôt dans un jeu de références qui, une fois encore, fait se croiser œuvre shakespearienne, mélodrame, cinéma et culture populaire des années 1970. Se sentant écrasé par la notoriété de sa mère, Terry contemple une affiche du nouveau spectacle dans lequel elle triomphe, The Way We Were (épisode 88). Non seulement l'arbre qui occupe la partie gauche de l'affiche est inspiré d'une des premières scènes d'Autant en emporte le vent où Scarlett et son père dialoguent sous un arbre du domaine au coucher du soleil, mais le titre de la pièce renvoie également à un drame sentimental des années 1970 (Nos plus belles années, en français) avec Barbra Streisand et Robert Redford (voir illustration 10).
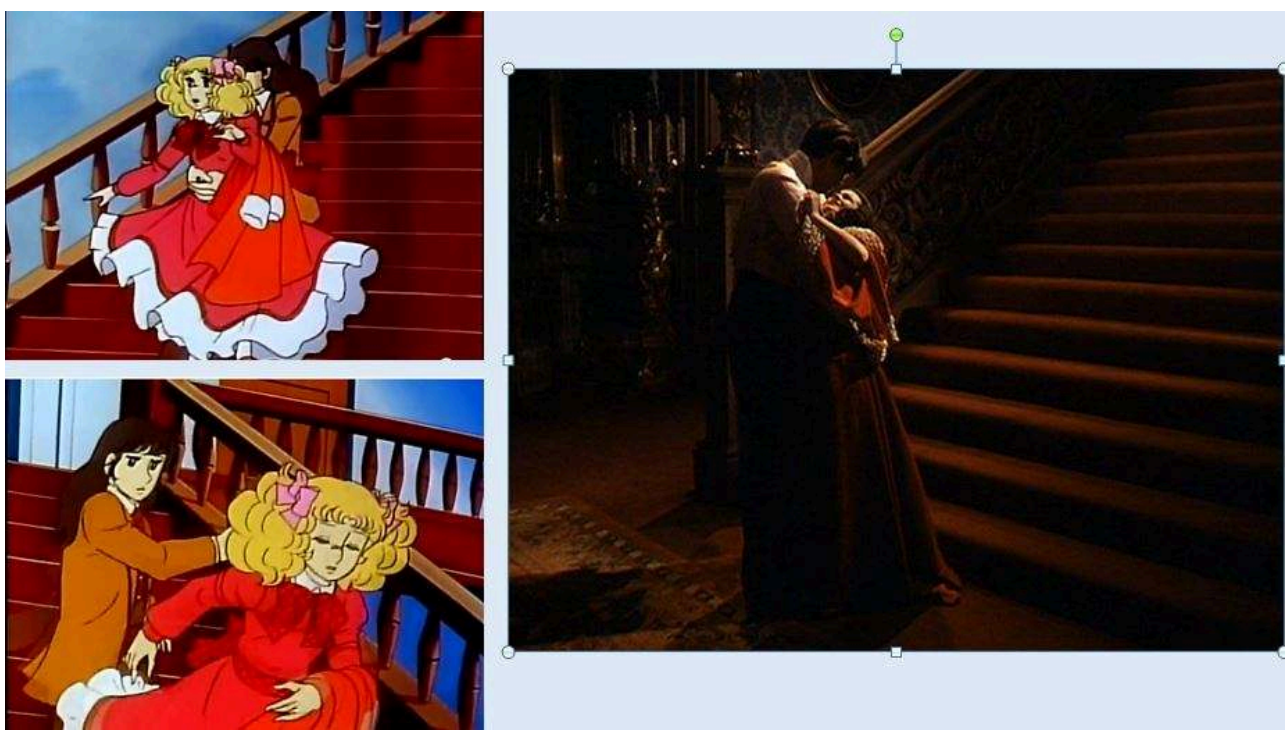

Illustration 9 : La scène d'adieu, capture d'écran de l'épisode 99, inspirée du film Autant en emporte le vent (réal. Victor Fleming, 1939), Rhett Butler (Clark Gable) et Scarlett O'Hara (Vivien Leigh) (capture d'écran, DVD, 2000).

Archive personnelle (Candy).

TOEl Animation Co., Ltd (Candy) / Warner Bros. (Gone With the Wind). Tous droits réservés. 


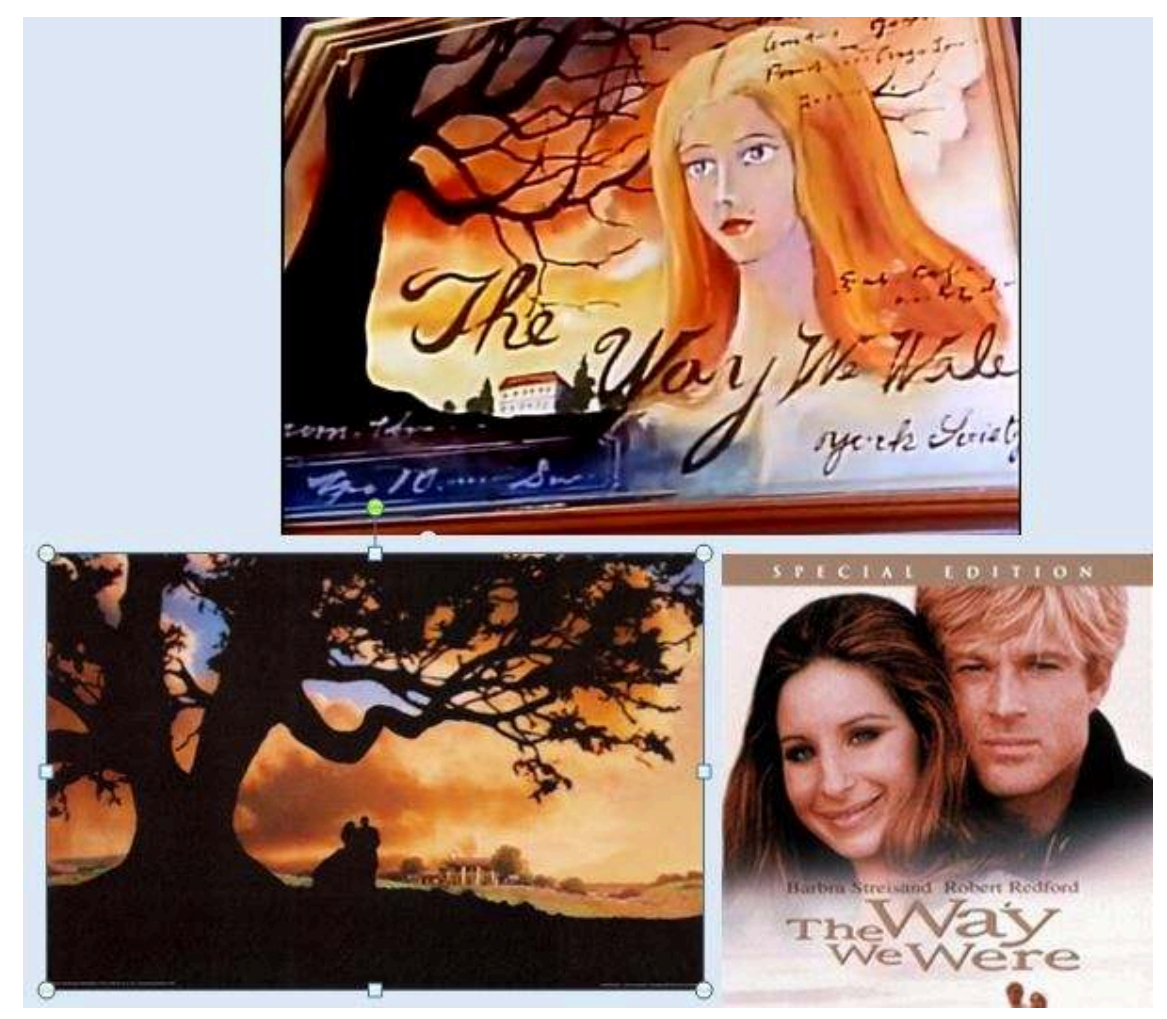

Illustration 10 : Affiche du spectacle d'Eléonore Baker, capture d'écran de l'épisode 88, inspirée du film Autant en emporte le vent (réal. Victor Fleming, 1939, capture d'écran, DVD, 2000) et du film Nos plus belles années (réal. Sydney Pollack, 1973), jaquette de DVD.

Archive personnelle (Candy).

TOEl Animation Co., Ltd (Candy) / Warner Bros. (Gone With the Wind) / Sony Pictures Entertainment (The Way We Were). Tous droits réservés.

Enfin, différents plans de Broadway mêlent des œuvres ouvertement américaines et des productions shakespeariennes. À l'épisode 91, l'affiche de Roméo et Juliette est précédée de celle d'un Western intitulé A Gunman No More. Blazing Western Action (voir illustration 11). Le titre fait directement allusion au volume A Gunman No More de la bande dessinée Rawhide Kid publiée par Marvel Comics en 1978 ; le sous-titre de cette série où superhéros et cow-boys se côtoient (Blazing Western Action As You Like It) associait d'ailleurs l'un des mythes américains les plus solidement ancrés dans l'imaginaire collectif - le grand Ouest - à l'une des comédies les plus célèbres de Shakespeare. On retrouve l'affiche du même spectacle à l'épisode 96, juste avant de découvrir celle de Roméo et Juliette, la devanture d'un restaurant américain venant cette fois-ci s'intercaler entre les deux. Ces différents plans témoignent des tensions que soulève la question d'une culture démocratique dans l'Amérique du long XIX siècle : si ces affiches donnent à voir un Shakespeare américanisé qui serait partie intégrante d'une culture populaire, le théâtre va aussi être présenté comme un espace de compartimentation sociale contre lequel les visions idéalisées de Terry et de Candy vont se heurter. 

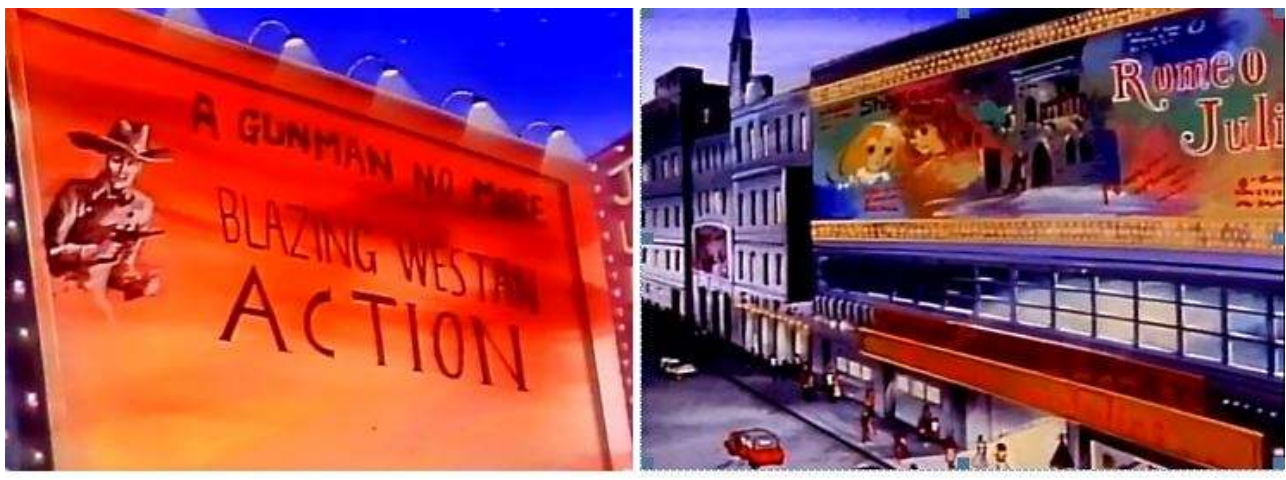

Illustration 11 : Affiche de Roméo et Juliette près de celle de $A$ Gunman No More, captures d'écran de l'épisode 91.

Archive personnelle.

TOEI Animation Co., Ltd. Tous droits réservés.

Candy propose un (long) trajet entre un Shakespeare littéraire et un Shakespeare joué sur scène. Il faut attendre pas moins de trente épisodes pour voir l'objet livresque se transformer en une représentation théâtrale, lorsque Terry joue Shakespeare pour la première fois dans l'épisode 73. Le théâtre est d'abord une aspiration merveilleuse avant que le rêve ne se confronte à la réalité.

La pièce Roméo et Juliette apparaît pour la première fois sous forme de livre dans l'épisode 44 , au cours duquel Terry refuse de se réconcilier avec sa mère qui est venue jusqu'en Écosse pour lui parler. Candy se fait médiatrice entre la mère et le fils et parvient à ouvrir les yeux de Terry sur ce qui l'unit à Eléonore : tous deux sont des admirateurs, lecteurs et disciples de Shakespeare. En désignant le livre ouvert sur les pages de la pièce ${ }^{13}$, Candy leur lance " Vous avez les mêmes goûts et vous avez le même sang ", comme si l'amour de Shakespeare se transmettait dans les gènes (de manière significative, l'épisode s'intitule «La Voix du sang »). Terry avoue finalement que lire la pièce était sa manière à lui de retrouver sa mère : «Toutes les répliques que je voulais souligner avaient déjà été soulignées de ta propre main" (voir extrait 1). La pièce apparaît d'abord comme un texte à lire et à annoter, qui se transmet de parent à enfant, un pont entre les êtres que la vie peut séparer. Parce que Shakespeare est ici un héritage alternatif qu'il appartient à chacun de s'approprier - un capital littéraire et culturel et non pas aristocratique et financier - la transmission de l'œuvre shakespearienne devient une promesse de renouvellement, d'émancipation et de changement de vie.

\section{Extrait 1}

Extrait 1 : La pièce de Shakespeare comme lien entre les générations, épisode 44.

Archive personnelle.

TOEl Animation Co., Ltd. Tous droits réservés.

Lorsque Candy découvre la passion de Terry pour le théâtre, elle s'en étonne (épisode 44 , voir extrait 2). Terry, qui n'a alors que seize ans, va alors expliquer pourquoi il rêve de devenir acteur :

TERRY. Quand tu seras devenue une vieille dame, tu seras toujours Candy.

CANDY. Bien sûr mais où veux-tu en venir?

TERRY. Et moi, quand j'aurai des cheveux blancs, je serai toujours Terry 
Grandchester.

CANDY. Oui mais je ne comprends toujours pas.

TERRY. Je veux dire par là que dans la vie courante on ne peut être autre chose que ce qu'on est. Mais qu'en jouant une pièce de théâtre, c'est tout à fait différent. On peut être mendiant ou prince, défenseur des opprimés, brasser le fer contre les traîtres, et gagner le cœur de sa belle. Une scène de théâtre, vois-tu, c'est tout un monde en miniature, un univers tout rempli de merveilles et de rêve éternel.

Alors que Terry met l'accent sur la fluidité des identités que permet la scène, les images à l'écran matérialisent son rêve.

Extrait 2

Extrait 2 : Le rêve de théâtre de Terry, épisode 44.

Archive personnelle.

TOEI Animation Co., Ltd. Tous droits réservés.

20 Le théâtre apparaît pour la première fois dans un fantasme en lien avec la scène très picturale du $\mathrm{XIX}^{\mathrm{e}}$ et de la première moitié du $\mathrm{XX}^{\mathrm{e}}$ siècle et ses effets protocinématographiques (comme la fermeture en iris, voir illustration 12) où le décor de la scène évoque le film Hamlet de Laurence Olivier (1948) et ses remparts brumeux (voir illustration 13).

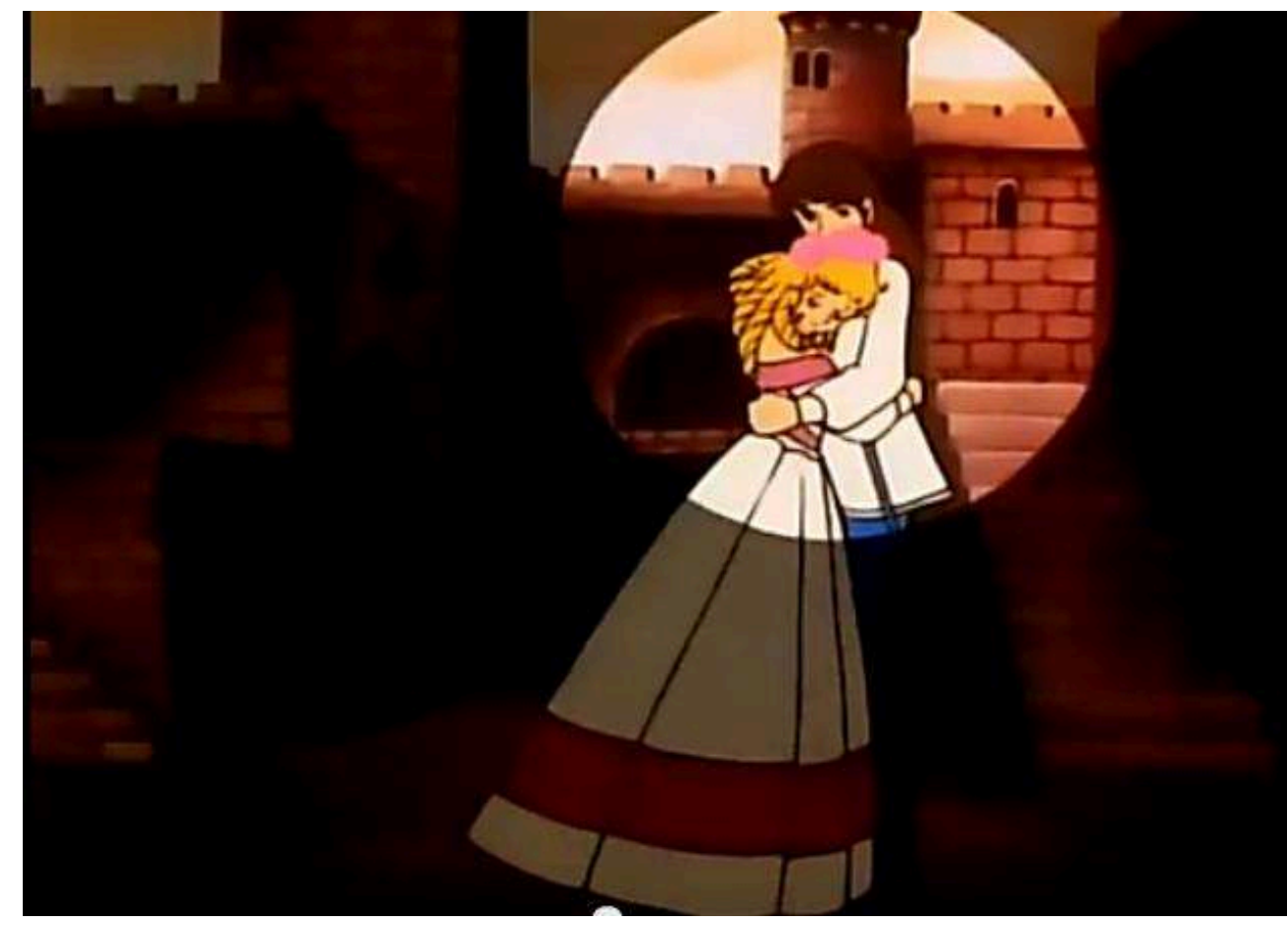

Illustration 12 : Effet proto-cinématographique dans le rêve de théâtre de Terry, capture d'écran de l'épisode 44.

Archive personnelle.

TOEI Animation Co., Ltd. Tous droits réservés. 


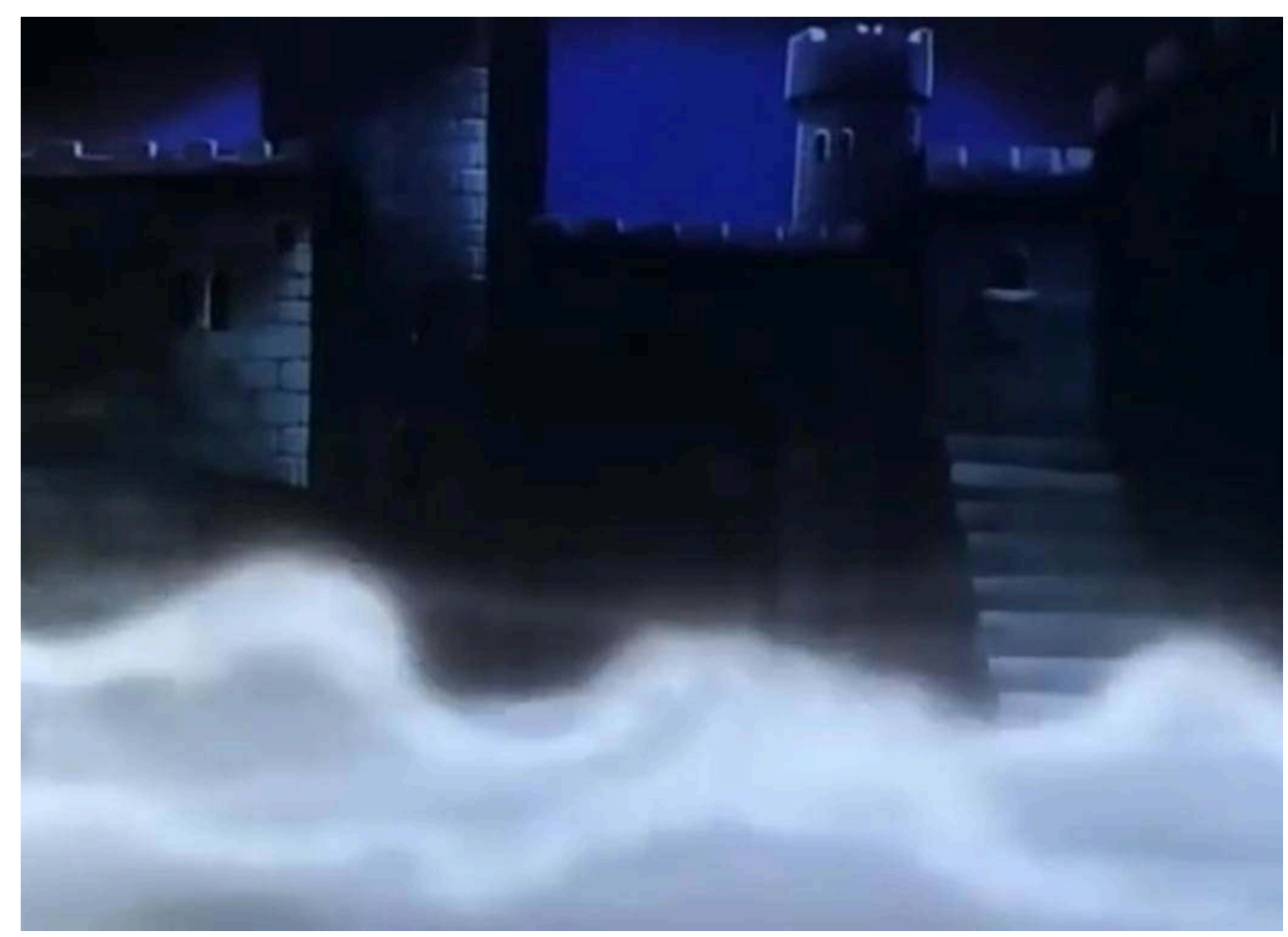

Illustration 13 : Rempart brumeux évoquant le Hamlet de Laurence Olivier (1948), capture d'écran de l'épisode 44.

Archive personnelle.

TOEI Animation Co., Ltd. Tous droits réservés.

Le désir de scène se fait aussi désir amoureux puisque la «belle " qu'on conquiert prend les traits de Candy, anticipant les échos entre la vie et le théâtre que tisseront les futurs épisodes. Le rêve de scène apparaît également comme un idéal social, Terry s'imaginant en prince et défenseur des opprimés. Cette vision du théâtre comme lieu idéalisé où la noblesse et la grandeur d'âme ne sont plus conditionnées par la naissance mais par la beauté du cœur s'inscrit dans l'héritage du théâtre américain populaire du $\mathrm{XIX}^{\mathrm{e}}$ siècle, et notamment des pièces qui virent triompher Edwin Forrest, première icône théâtrale américaine.

Soutien indéfectible du Parti Démocrate et ardent défenseur de la mobilité sociale, Forrest est connu aussi bien pour ses interprétations du répertoire shakespearien que pour ses rôles dans des pièces écrites sur mesure qui célèbrent les valeurs de l'Amérique jacksonienne. Il triomphe ainsi en incarnant Spartacus (The Gladiator, de Robert Montgomery Bird, 1828) ou Jack Cade - dans une pièce écrite par Robert Conrad et produite en 1841 qui cherche à réhabiliter la figure du rebelle allègrement malmenée par Shakespeare; il est par là-même emblématique des tensions au cœur d'une américanité qui se construit dans un fantasme de rupture avec l'Ancien Monde tout en se nourrissant d'une culture européenne qu'elle réinvente. Terry cherche à s'émanciper de la culture anglaise aristocratique et rêve d'incarner, comme Forrest, des héros qui opposent à la légitimé généalogique des puissants une noblesse naturelle remettant en cause les hiérarchies sociales de l'Ancien Monde. Le premier rôle de Terry est tout à fait révélateur à cet égard. C'est en incarnant sur scène le Jeune Siward dans Macbeth qu'il se fait remarquer du public. Si la première et la dernière répliques de Macbeth sont coupées, le reste de la scène est rendu dans une traduction qui en restitue l'essentiel. Le 
texte shakespearien fait ainsi son entrée dans l'anime à travers une scène dénonçant l'exercice d'un pouvoir tyrannique sur le point de s'effondrer. Non seulement la thématique informe la plupart des pièces historiques américaines des années 1780 à la fin du XIXe siècle et constitue un motif sans cesse rejoué sur les planches de la jeune nation, mais le choix de cet extrait témoigne du goût cultivé par les Américains de l'époque pour les pièces shakespeariennes soulevant la question du pouvoir despotique (Richard III, Macbeth et Coriolan sont d'ailleurs des pièces que Forrest affectionne particulièrement $\left.{ }^{14}\right)$. Ce passage est d'ailleurs précédé d'une vue de la Statue de la Liberté, qui métaphorise cette appropriation de l'idiome shakespearien à travers le prisme américain.

La séquence en Écosse où Terry exprime son rêve d'acteur est ensuite remémorée, revisitée et réécrite en palimpseste tout au long du feuilleton. Elle est présentée comme une scène cruciale scellant le destin des protagonistes alors qu'elle-même n'est jamais stabilisée. Candy s'en souvient lorsque, passagère clandestine dans un cargo en partance pour les États-Unis, elle pense à Terry, à « ses rêves et sa vocation » (épisode 55). Alors qu'elle est sur le point de revenir à l'orphelinat où elle a été élevée (épisode 57), elle se remémore la scène où les dialogues se modifient sous l'effet du souvenir (voir extrait 3) :

CANDY. Tu voudrais faire du théâtre, n'est-ce pas?

TERRY. Oui, j'en rêve. Parce que le théâtre, vois-tu, c'est de la magie. Dans la vie, on ne peut être que soi-même, mais sur scène on incarne mille personnages, on peut être prince ou mendiant, poète ou paysan. Le métier d'acteur est le plus beau métier du monde, Candy. Je serai acteur et j'écrirai des pièces.

\section{Extrait 3 : Candy se remémorant le rêve de théâtre de Terry, épisode 57.}

Archive personnelle.

TOEl Animation Co., Ltd. Tous droits réservés.

Si le titre de Roméo et Juliette est évoqué par les personnages dès l'épisode 44, le nom de Shakespeare n'apparaît pas avant l'épisode 73, lorsque Candy lit à haute voix un article dans le journal : "Terrence triomphe dans Shakespeare à Broadway ». Le jeune homme qu'elle a connu semble se superposer parfaitement à la star du journal : "Tu n'as pas changé, Terry. Plus d'assurance dans le regard, peut-être. Broadway! Tu as enfin réalisé le rêve de ta vie ». La réussite de Terry renvoie Candy, une fois encore, à son souvenir d'Écosse, à cette scène-clé qui ne cesse de ressurgir, d'être adaptée et de hanter l'intrigue (voir extrait 4$)$ :

CANDY. Shakespeare ? C'est à toi, ce livre ? Si tu le lis, c'est que tu aimes le théâtre.

TERRY. Non.

CANDY. Regarde, c'est plein de notes dans la marge et entre les lignes au point qu'on ne peut plus lire le texte.

TERRY. Bon, je veux bien l'avouer. J'aime le théâtre. Je devrais au contraire le détester mais je l'aime.

Extrait 4 : Candy se remémorant encore une fois le rêve de théâtre de Terry, épisode 73. 
Dans ce nouveau souvenir, le nom de la pièce disparaît au profit de l'auteur dans un discours qui retourne aussi, paradoxalement, à l'importance des annotations et d'une lecture si personnelle qu'elle peut en venir à effacer le texte. Les souvenirs répétés de Candy ancrent toujours le passé dans le présent et invitent les jeunes spectateurs à apprécier les écarts qui se créent entre un but que l'on s'est fixé et sa réalisation. La vision de Terry comme acteur se fond dans un plan sur la Statue de la Liberté (voir illustration 14): le théâtre est, jusque-là, envisagé comme un rêve d'émancipation. Shakespeare est un jalon dans un parcours initiatique pour devenir soi-même. Cependant, ce rêve d'affranchissement par le théâtre se heurte à des réalités économiques, sociales et matérielles que l'anime met au jour.
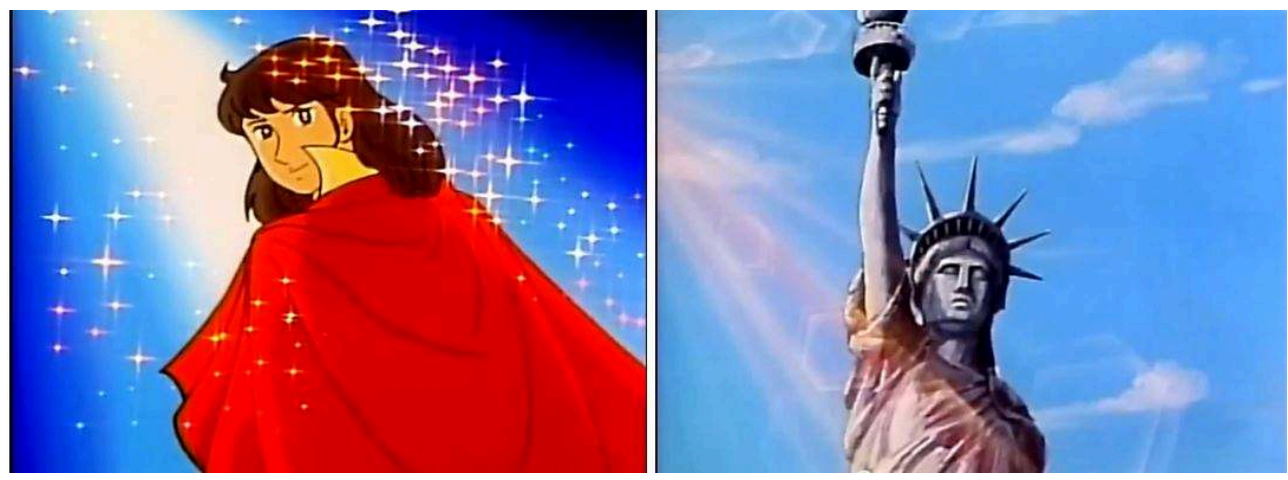

Illustration 14 : L'acteur comme homme émancipé dans Candy, captures d'écran de l'épisode 73.

Archive personnelle.

TOEl Animation Co., Ltd. Tous droits réservés.

Dès qu'une pièce de Shakespeare est effectivement jouée sur scène (Macbeth dans l'épisode 73), les menaces qui planent sur la troupe sont soulignées. Alors que la Première Guerre mondiale éclate en Europe, les acteurs et techniciens s'interrogent (voir extrait 5):

- Une guerre aura obligatoirement des répercussions très fâcheuses sur le théâtre.

- Oui, mais ça ne pourra pas aller jusqu'à la censure?

- Sans doute mais le public sera moins nombreux à nous applaudir.

- Je ne suis pas de votre avis. L'Amérique est loin de l'Europe. Ça ne nous concerne pas.

\section{Extrait 5}

Extrait 5 : Le théâtre et la déclaration de la Première Guerre mondiale, épisode 73.

Archive personnelle.

TOEI Animation Co., Ltd. Tous droits réservés.

Le théâtre, dans son économie comme dans ses choix artistiques, est montré en lien avec les événements du monde. Le feuilleton dit clairement aux enfants que les représentations théâtrales n'ont pas lieu dans une «bulle » de fiction mais sont en prise directe avec la société, ses violences et ses injustices. Avant la première du Roi Lear à Chicago (épisode 78), Terry refuse de participer aux dernières répétitions. Suzanne Marlowe, qui joue Cordélia, le retrouve sur les toits du théâtre à jouer de l'harmonica en solitaire. Terry lui expose ses raisons en soulignant le contexte social de la représentation (voir extrait 6): 
TERRY. Il paraît que nous jouons pour la haute société.

SUZANNE. Oui, c'est une soirée de gala pour une œuvre de bienfaisance.

TERRY. Une soirée de gala réservée uniquement à un public de privilégiés par leur argent ou leur position sociale.

SUZANNE. Bien sûr, mais le prix des places ira aux œuvres de charité.

TERRY. C'est ce qu'on dit. Non, je ne jouerai pas. [...] Crois-tu donc vraiment que les pauvres ont seulement besoin d'argent, qu'ils n'ont pas eux aussi soif de culture? [...] La culture n'est pas uniquement réservée à ceux qui ont les moyens de s'offrir une soirée de gala, mais à tous ceux qui ont le goût et le sens du beau.

Extrait 6 : Terry exprimant sa vision du théâtre avant la première du Roi Lear, épisode 78.

Archive personnelle.

TOEl Animation Co., Ltd. Tous droits réservés. d'un système paternaliste où les riches justifient leurs privilèges à travers des œuvres de charité pour les plus démunis; Terry, quant à lui, remet en question la hiérarchie sociale et défend une culture démocratisée à l'intérieur même d'un dessin animé qui s'inscrit dans la culture populaire. Selon lui, Shakespeare ne devrait pas être un simple divertissement réservé à certaines catégories sociales qu'il contribue à constituer.

Juste avant le lever de rideau, Terry, qui doit jouer le roi de France, reste introuvable. Il s'est réfugié au troisième balcon. Symboliquement, l'acteur qui défend le peuple a non seulement franchi le quatrième mur, brouillant ainsi les frontières entre la scène et la salle, mais il s'est aussi installé là où les places sont les moins chères. Hattaway, le meneur de la troupe qui interprète Lear, va lui parler. Les deux comédiens sont déjà en costume ; la confrontation de Lear et du roi de France se joue ainsi dans la vie avant d'avoir lieu sur scène ${ }^{15}$ (voir extrait 7).

Extrait 7

Extrait 7 : Terry et Hattaway : deux visions opposées du théâtre, épisode 79.

Archive personnelle.

TOEI Animation Co., Ltd. Tous droits réservés.

Le jeune acteur s'étonne de ce que le troisième balcon soit entièrement vide. Hattaway lui explique que seuls « les gens de la meilleure société » ont été invités, ce à quoi Terry répond qu'ils auraient pu « distribuer ces places à (de) pauvres gens ». Hattaway prône un théâtre déconnecté de la société dans laquelle il se déploie («Nous jouons la comédie. Le reste ne nous concerne pas») et dont l'absence de toute forme d'engagement perpétue et cautionne des inégalités de classe. Terry, au contraire, réaffirme la fiction et la scène comme utopie sociale et agent de transformation. Cependant, cette rébellion de Terry est de courte durée puisqu'il joue finalement le roi de France devant ce public privilégié. L'anime a alors l'occasion de montrer les conséquences de ce « Shakespeare pour les riches».

Candy, qui a renoncé à être un membre de la richissime famille André pour suivre la voie qu'elle s'est choisie - celle d'infirmière -, subit de plein fouet les formes d'exclusion sociale que génère le théâtre. Son parcours au fil des épisodes, des milieux les plus aisés aux plus modestes, son refus de devenir une riche héritière et sa décision d'entreprendre des études afin de gagner sa vie sont emblématiques de son 
américanité. Comme elle le déclare dès l'épisode 21, au cours duquel elle est censée apprendre l'arbre généalogique des André et ne comprend pas pourquoi elle doit se faire aider pour des tâches qu'elle peut accomplir elle-même : «Les gens riches n'ont rien à faire ». Dès le second épisode, elle affirme déjà : « Dans la vie, on ne peut compter que sur soi-même ». Mais cette quête d'indépendance lui joue des tours et l'anime met en avant les enjeux de classes sociales qui conditionnent la "sortie au théâtre » : alors qu'elle cherche à retrouver Terry qu'elle n'a pas revu depuis un an, Candy apprend qu'elle ne pourra pas assister à la représentation du Roi Lear. Eliza, la riche pimbêche, se délecte à lui annoncer que l'unique représentation «n'est pas publique mais pour un gala de charité... Seules les personnes du grand monde y seront invitées » (épisode 78). Même quand elle parvient à obtenir une place grâce à ses amis, son métier d'infirmière s'interpose : elle est de garde ce soir-là.

Lorsque Candy parvient difficilement à se faire remplacer à l'hôpital et arrive au théâtre à la dernière minute, c'est pour être ramenée à un statut social qui n'a pas sa place au théâtre, faute d'en maîtriser les codes. Eliza lance : «C'est une tradition très respectable. Arriver à l'heure est la moindre des politesses " (épisode 79) et la grandtante Elroy lui interdit l'accès à la loge de la famille André. Le théâtre est vu comme un univers clos qui, ce soir-là, rejette les travailleurs et les non-initiés. Candy erre alors dans le théâtre et ses coulisses pour trouver une place. La pièce commence mais les jeunes téléspectateurs n'en voient et n'en entendent que des bribes. La représentation est filtrée à travers celle qui ne peut pas y assister de manière légitime et qui se fait refouler de tous les endroits où elle tente de s'installer (voir extrait 8).

Extrait 8 : Candy tentant d'assister à la représentation du Roi Lear, épisode 79.

Archive personnelle.

TOEl Animation Co., Ltd. Tous droits réservés.

La séquence nous offre ainsi des perspectives inédites et fluctuantes sur la scène, révélant que la réception d'un spectacle varie en fonction du point de vue et d'écoute. Candy arrive sous la scène où elle chuchote « J'entends bien mais je ne vois pas grandchose ", et trouve finalement refuge au poulailler, là où Terry s'était assis un peu plus tôt, comme de manière prophétique. Le feuilleton met ainsi en avant la notion de place à " visibilité réduite " (restricted view) et renforce l'idée, très en vogue au XIX ${ }^{\mathrm{e}}$ et au début du XXe siècle, qu'une pièce de Shakespeare doit être vue avant d'être entendue.

Candy voit finalement Terry sur scène et, à la fois admirative et amoureuse, s'extasie jusqu'à en pleurer (voir illustration 15). L'acteur shakespearien est construit comme un être merveilleux et charismatique qu'on admire et chérit, mais aussi comme une star inaccessible. Peu importe que Candy ait vécu une histoire avec le jeune homme un an auparavant. Elle est maintenant reléguée au rang de simple admiratrice qui ne peut accéder à la loge de l'acteur et qui, à la sortie des artistes, doit jouer des coudes parmi la meute des chasseuses d'autographe (voir illustration 16) ${ }^{16}$. Terry ne repère pas Candy dans la foule et monte dans le fiacre avec sa partenaire de scène pour rejoindre une fête mondaine où il fait tout pour refuser les invitations à des " garden parties ». 

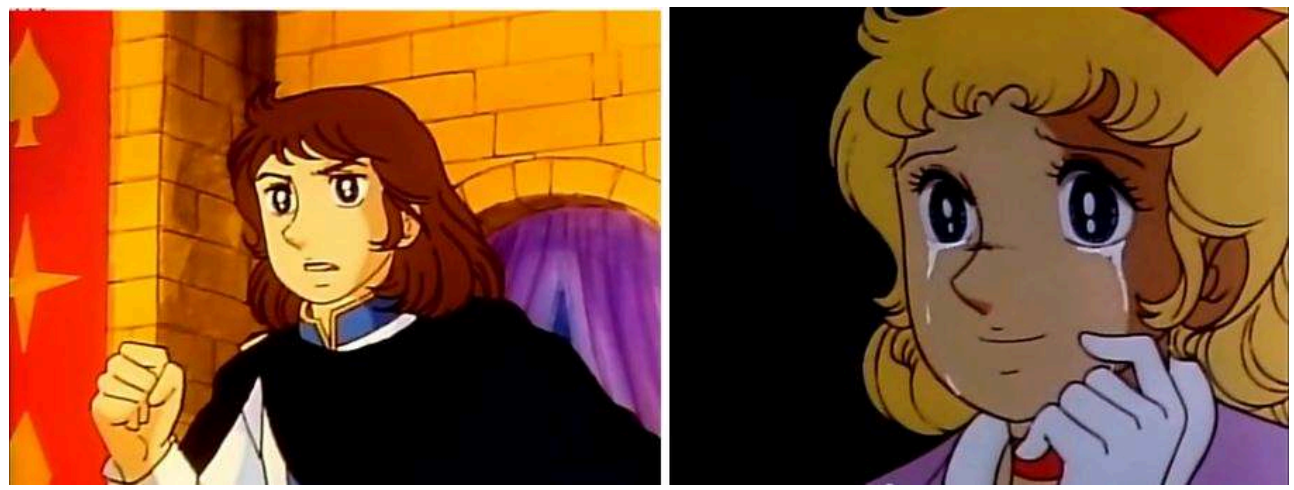

Illustration 15 : Candy émue devant l'acteur shakespearien, captures d'écran de l'épisode 79

Archive personnelle.

TOEI Animation Co., Ltd. Tous droits réservés.

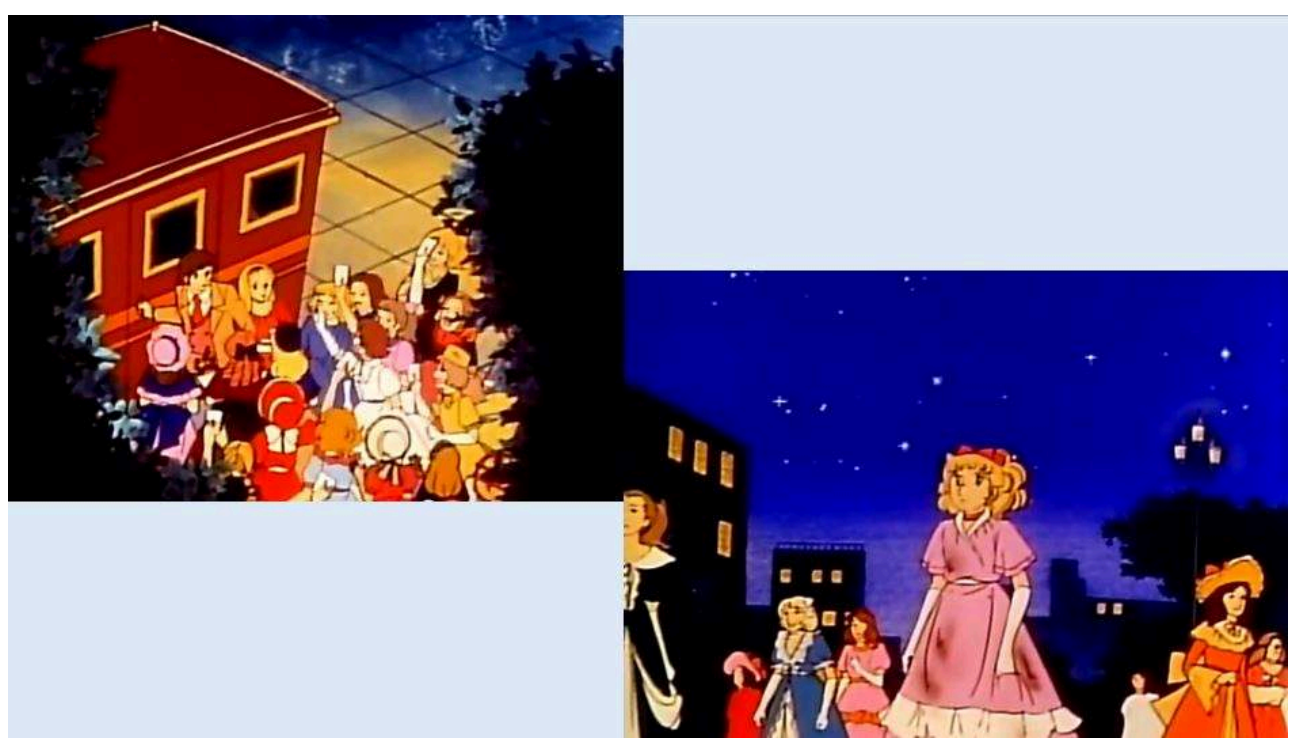

Illustration 16 : Candy dans la foule d'admiratrices, captures d'écran de l'épisode 79.

Archive personnelle.

TOEI Animation Co., Ltd. Tous droits réservés.

41 Une vingtaine d'épisodes plus tard, le feuilleton rejoue la partition en variation. Terry a remis à Candy une invitation pour assister à la première de Roméo et Juliette, mais Daniel et Eliza déchirent son billet par jalousie (épisode 98). Candy est une nouvelle fois ramenée à sa condition sociale, affronte les rouages administratifs élitistes du théâtre (un employé lui signale que son billet n'est plus valable et que la pièce se joue à guichet fermé) et se heurte à l'intransigeance des procédures qui interdisent l'accès à la loge des acteurs. Là encore, elle est prise pour une admiratrice anonyme que Terry refuse de recevoir. Candy entre finalement par l'arrière du théâtre, symbole de la subversion qu'elle représente pour cette culture théâtrale réservée aux élites. Surprise sans billet, elle est priée de prendre la porte avant d'être sauvée par Karine Kliss, l'une des actrices, qui la reconnaît. Le programme sur lequel Karine appose son autographe devient un laisser-passer. L'actrice acquiert une autorité tandis que la sympathie que 
Candy inspire autour d'elle vient remplacer le capital financier et social qui lui fait défaut.

La trajectoire shakespearienne de Terry est, elle aussi, construite comme un parcours du combattant, à la fois cohérent, rapide et semé d'embûches. Ses rôles gagnent progressivement en importance : le jeune Siward dans Macbeth, puis le roi de France dans Le Roi Lear, jusqu'à Roméo. Le feuilleton met l'accent sur le long chemin qui mène de l'audition à la sélection, des nombreuses répétitions jusqu'à la représentation théâtrale. L'audition de Terry pour obtenir le rôle de Roméo (épisode 87) a lieu en même temps que l'examen de Candy pour devenir infirmière (voir extrait 9).

Extrait 9

Extrait 9 : L'audition de Terry et l'examen de Candy, épisode 87.

Archive personnelle.

TOEI Animation Co., Ltd. Tous droits réservés.

Que les deux événements soient montrés en parallèle souligne d'ailleurs que la mission sociale du comédien est tout aussi essentielle que celle d'infirmière. L'audition met l'accent sur l'attente des acteurs, le trac face au jury, la peur d'oublier son texte, les décisions du metteur en scène de faire auditionner tel acteur avec tel autre. Le feuilleton dévoile aux enfants le processus de production, la notion de casting et de représentation fluctuante. Durant l'audition, la scène du balcon est jouée par un couple d'acteurs puis par un autre (voir illustrations 17 et 18), révélant aux jeunes téléspectateurs le fait qu'un rôle peut être interprété de manière différente en fonction des comédiens.

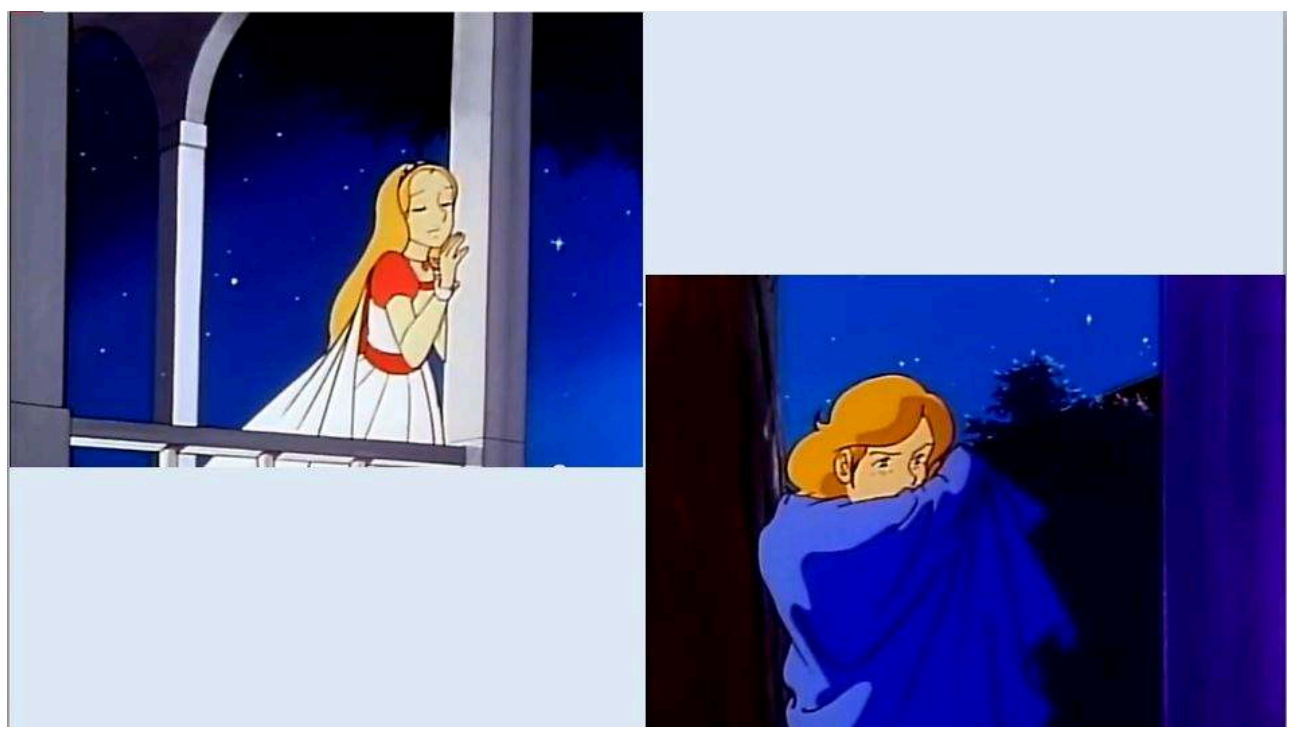




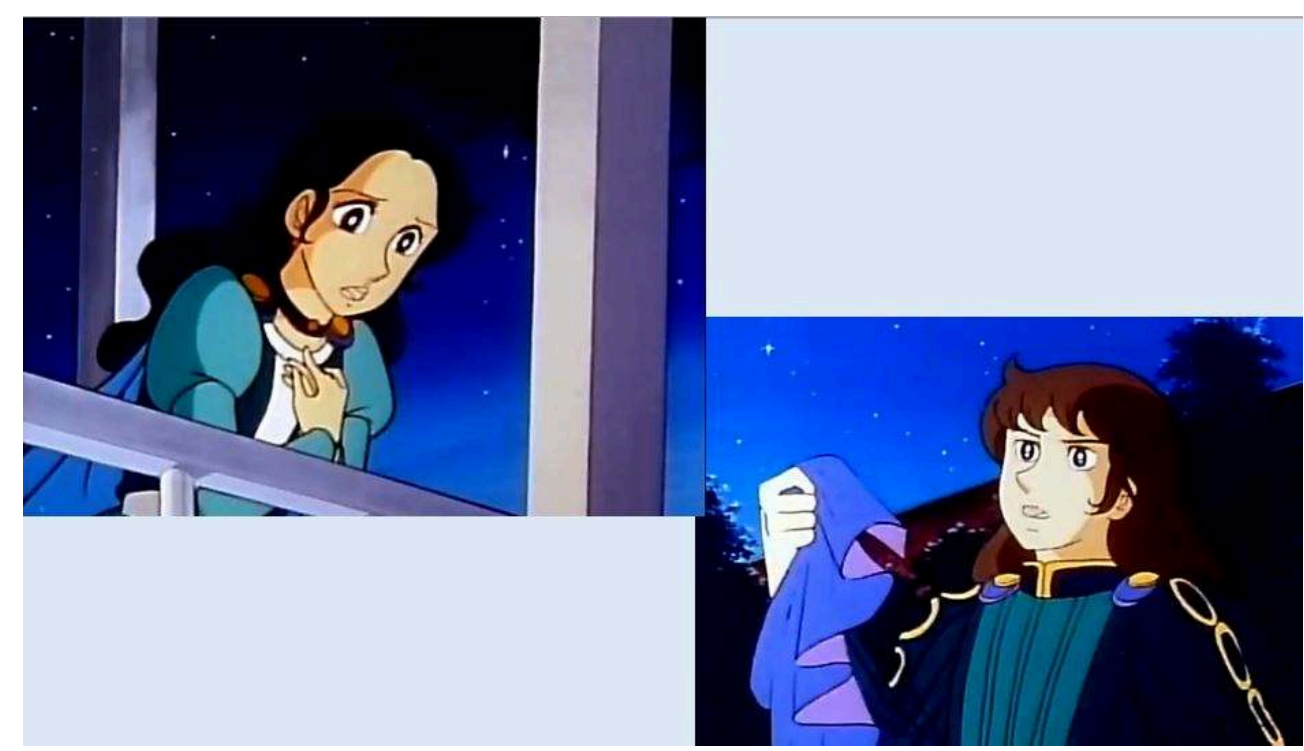

Illustrations 17 et 18 : Les deux couples d'acteurs jouant Roméo et Juliette pendant les auditions, captures d'écran de l'épisode 87.

\section{Archive personnelle}

TOEI Animation Co., Ltd. Tous droits réservés.

Le feuilleton aborde aussi la question du passe-droit, de la carrière que l'on doit uniquement à son nom. Parce qu'Éléonore Baker assiste en secret à l'audition de son fils, les autres acteurs pensent que Terry a obtenu le rôle par relations et l'appellent ostensiblement «Terry Baker » (épisode 88). Le jeune homme, qui a tenté de se libérer de son patronyme anglais en partant pour les États-Unis, se retrouve à porter le poids du nom maternel. Hattaway, le directeur de la troupe, doit rassurer Terry: «Ni les relations ni les liens de famille n'ont la moindre influence sur mes décisions en ce qui concerne la profession. [...] Si tu as obtenu le rôle de Roméo, tu le dois à ton talent et à lui seul [...] Le métier de comédien est l'un de ceux où l'on se fait le moins de cadeaux ». Non seulement la vie d'acteur n'est pas idéalisée, mais elle est présentée comme un sacerdoce. Terry loge dans une petite chambre quasi monacale. Une affiche d'Hamlet au mur en constitue la seule décoration et rappelle une dévotion complète à l'art (voir illustration 19).
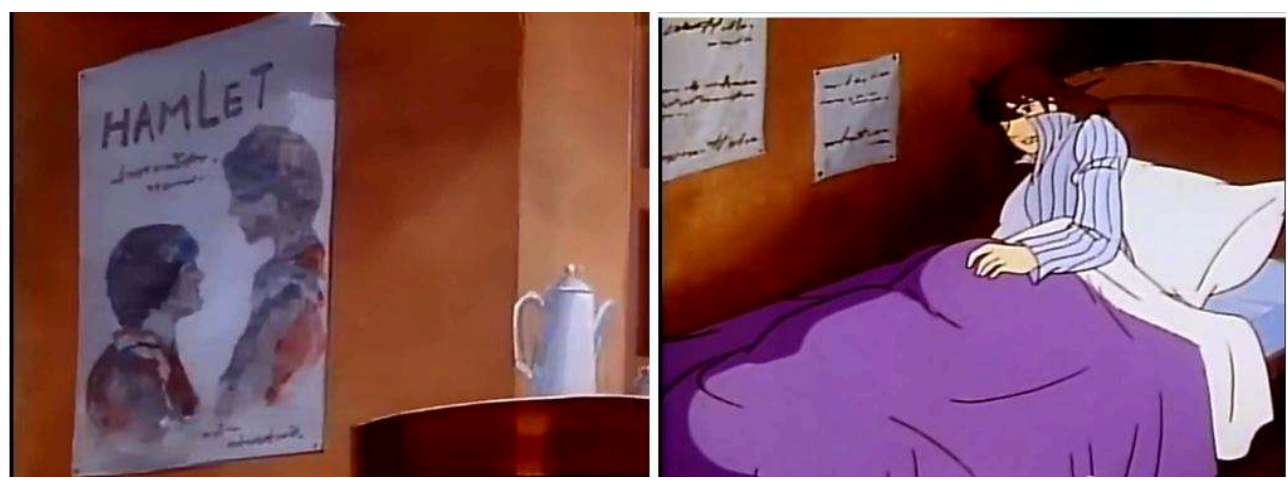

Illustration 19 : L'affiche d'Hamlet dans la chambre monacale de Terry, captures d'écran de l'épisode 90.

Archive personnelle.

TOEI Animation Co., Ltd. Tous droits réservés. 
Dans Candy, les gens du spectacle acquièrent une dimension sacrificielle - qui participe des accents mélodramatiques de l'anime. La matérialité du théâtre brise littéralement les rêves. Le drame arrive, en effet, par le biais d'un objet, un projecteur, qui se détache pendant une répétition de Roméo et Juliette dans l'épisode 95 (voir illustration 20). Suzanne se jette sur Terry pour le sauver, mais elle est blessée par l'objet et doit être amputée d'une jambe. Après l'accident, la pièce trouve des échos à l'hôpital : Terry, encore dans son costume de Roméo, est réconforté par Hattaway, habillé en Frère Laurent (voir illustration 21). Le metteur en scène remplace rapidement Suzanne par Karine Kliss, et les répétitions continuent comme si de rien n'était. Terry est scandalisé de voir que «M. Hattaway [...] n'a qu'un seul souci en tête : le succès de la pièce ", alors que Suzanne « est là-bas sur son lit d'hôpital ».

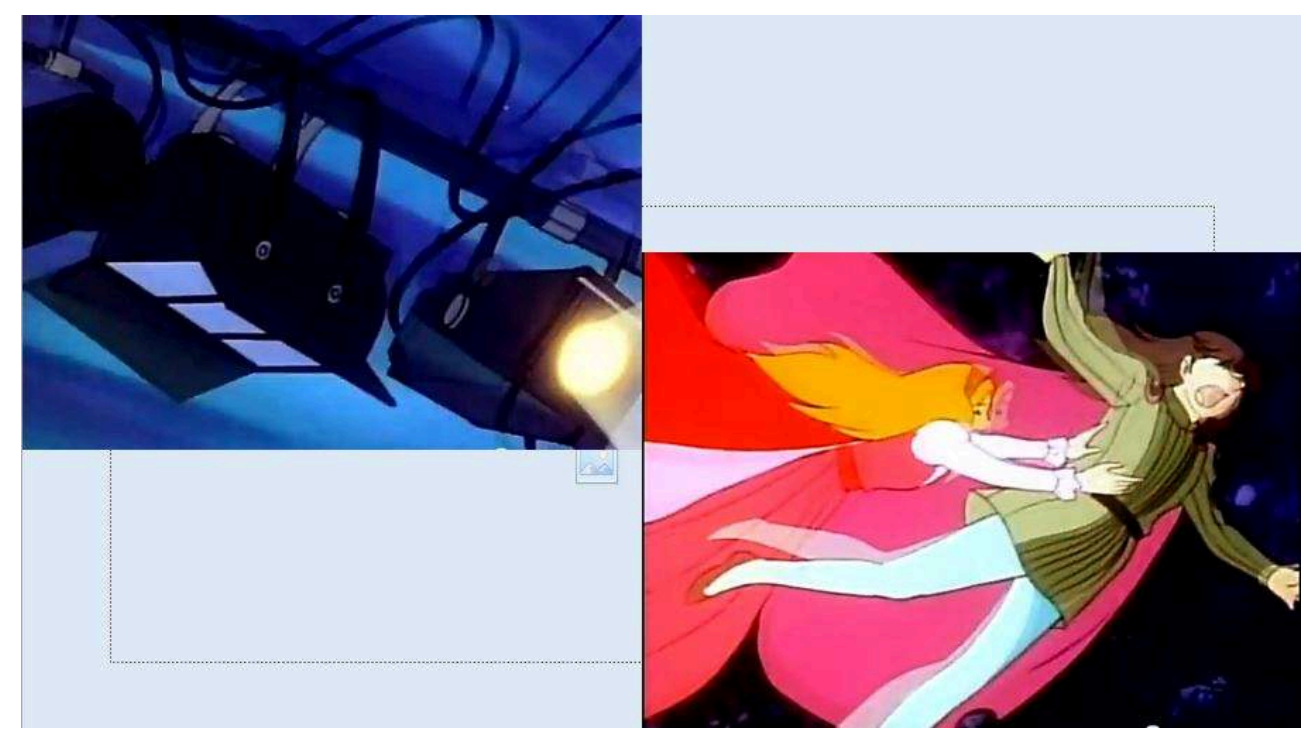

Illustration 20 : L'accident quand le projecteur se détache, captures d'écran de l'épisode 95.

Archive personnelle.

TOEI Animation Co., Ltd. Tous droits réservés. 


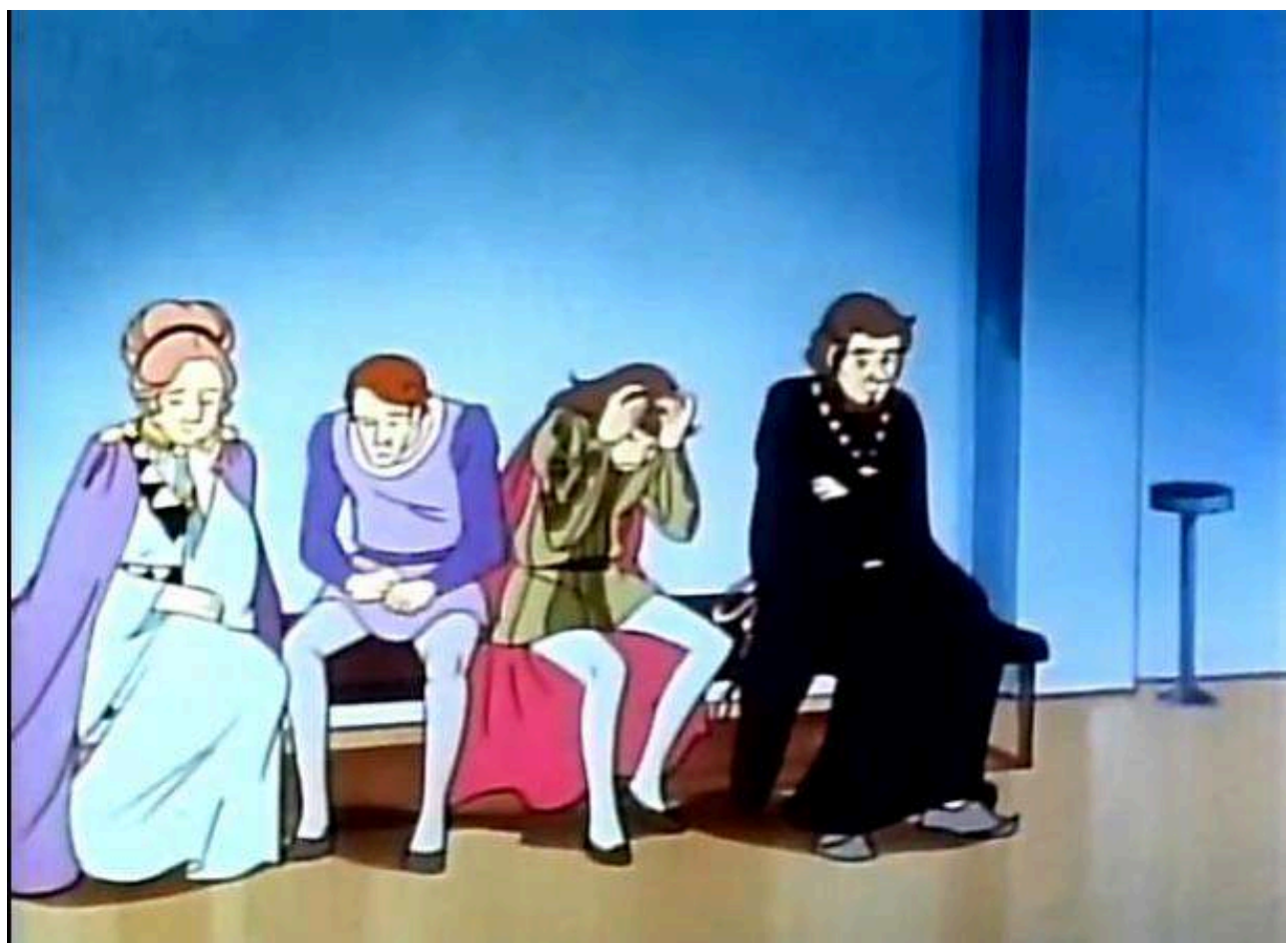

Illustration 21 : Les comédiens à l'hôpital, encore en costumes de scène, capture d'écran de l'épisode 95.

Archive personnelle.

TOEI Animation Co., Ltd. Tous droits réservés.

La tragédie est annoncée à plusieurs reprises dans le feuilleton, particulièrement dans l'épisode 94 où Candy fait la rencontre de Gilles, dont le père s'occupait des projecteurs lors de la représentation du Roi Lear. Nous revoyons alors en flashback la production, mais du point de vue du machiniste, et apprenons, par son fils, que cet homme "souffrait beaucoup en faisant son travail, mais il le faisait avec le plus grand courage sans jamais se plaindre. Personne ne s'est jamais aperçu de rien ». Une fois encore, le récit refuse d'idéaliser le monde du spectacle et montre aux jeunes téléspectateurs les soi-disant « petites mains » dont l'abnégation et le sacrifice préfigurent l'accident.

C'est en effet toute une économie, ainsi qu'une sociologie, du théâtre qui est mise au jour dans Candy. Aux travailleurs de l'ombre, s'opposent les riches spectateurs dont les commérages retentissent dans la salle et le foyer, tranchant avec le grand texte de Shakespeare. Le jeu des acteurs fait l'objet de jugements après le spectacle (« Ils ont tous été merveilleux, surtout celui qui jouait le roi de France ", "Oh oui, j'en suis toute remuée ", épisode 79) et même avant la représentation ("Certains échos laissent espérer que le spectacle sera réussi ", "J'ai entendu dire de mon côté que Terrence Grandchester était génial, j'ai hâte de le voir à l'œuvre ", épisode 98). Les spectateurs se joignent au chœur de la critique (que Terry dédaigne ouvertement) et contribuent à diffuser les ragots colportés par les journaux à scandales.

Les hauts et les bas que connaît la carrière de Terry se reflètent dans la presse (illustration 22). Au plus fort de son succès, Terry fait l'objet de critiques dithyrambiques: "Il a su renouveler un texte figé par des siècles de tradition et apporté un sang nouveau à la tragédie » (épisode 73), « Une nouvelle étoile est née. La 
reprise de Roméo et Juliette à Broadway par la troupe Strasford confirme le talent, disons même le génie, du jeune Terrence Grandchester " (épisode 101). Terry devient aussi l'objet d'un album de coupures de presse regroupées par des admiratrices (épisode 102). Mais lorsque, suite à l'accident de Suzanne, Terry sombre dans l'alcool, quitte la troupe et erre de ville en ville, les magazines à scandales ont tôt fait de descendre en flamme celui qu'ils avaient porté aux nues: "Un prince déchu: le célèbre acteur Terry Grandchester vient de causer à ses admirateurs une immense déception ». De l'étoile montante au prince déchu, Terry incarne ainsi une vraie "roue de la fortune" shakespearienne, en même temps qu'il suit les codes du mélodrame. Les jeux de miroirs - souvent déformants - entre l'œuvre shakespearienne et l'existence des personnages informent, en effet, l'intrigue de l'anime.
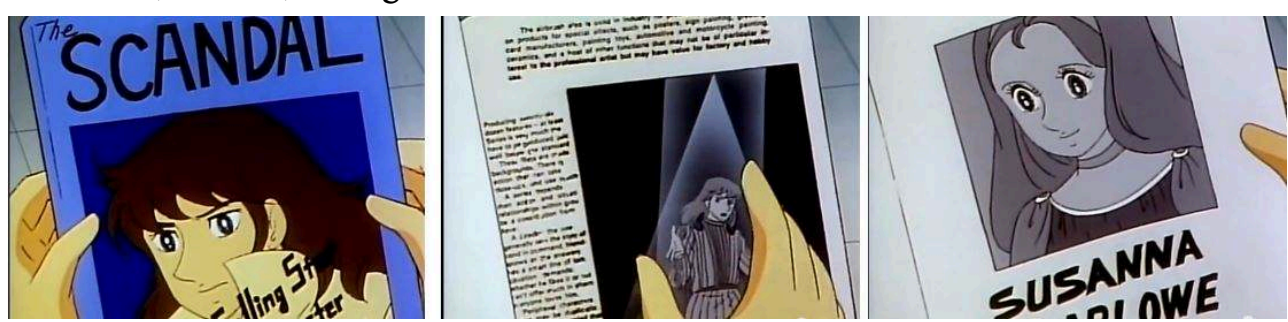

Illustration 22 : L'acteur shakespearien dans la presse à scandale, captures d'écran de l'épisode 111.

Archive personnelle

TOEl Animation Co., Ltd. Tous droits réservés.

Candy reprend et diffracte des motifs des pièces shakespeariennes: spectralité, contretemps, lettres non transmises, effets d'annonce tragiques, structurent le récit. La première rencontre entre Terry et Candy est marquée par un brouillard qui fait surgir le fantôme d'Anthony. Leur relation est ainsi hantée par le précédent amour de la jeune fille. À partir du moment où elle prend conscience de ses sentiments pour Terry, les deux jeunes gens sont séparés et ne vont cesser de se croiser et de se manquer de peu. L'intrigue de Candy est un miroir déformant, ainsi qu'une chambre d'échos, où se reflètent et se diffractent les amants maudits de Roméo et Juliette - la dessinatrice, Yumiko Igarashi, a d'ailleurs adapté la pièce en manga en 2013. La missive que le Frère Laurent envoie à Roméo mais qui n'arrive jamais trouve son pendant dans les lettres que Candy envoie à Terry mais que Suzanne Marlowe, jalouse, intercepte. À l'image de Roméo, qui trouve le corps de Juliette inanimé mais encore chaud, Candy court vers le lieu où elle pense revoir Terry et y trouve seulement la tasse de thé " encore chaude " qu'il vient de laisser (épisode 58). La sexualité adolescente est suggérée ("Si j'étais un adulte, je l'aurais enlevée. Nous serions partis ensemble loin d'ici à la recherche d'une autre vie, à la recherche du bonheur ", pense Terry), mais l'amour n'est finalement jamais consommé. Le feuilleton entier se construit ainsi autour d'une frustration amoureuse et narrative.

51 À travers les résurgences de Roméo et Juliette, les constructions genrées se manifestent dans un jeu ambivalent où les identités semblent parfois troublées ou fluctuantes, mais où toute forme de transgression n'est que temporaire. Candy contrevient fréquemment aux codes de genre : contrairement à Annie, la jeune fille sage avec qui elle a grandi, Candy grimpe aux arbres, refuse souvent d'obéir aux ordres et n'hésite pas à se battre. Lors du festival de mai organisé au collège de Saint Paul, elle se retrouve consignée et n'a pas le droit de participer au bal masqué. Le grand-oncle William André, qui l'a 
adoptée, lui fait parvenir un colis dans lequel elle découvre deux déguisements, une robe de Juliette et un costume de Roméo. Candy se demande si « c'est pour un garçon ou pour une fille » et doit choisir son genre. Elle décide tout d'abord de se déguiser en garçon. Cette subversion des normes s'accompagne immédiatement d'une transgression de l'espace : Candy s'échappe de sa cellule par la fenêtre et se rend au bal où elle fait quelques pas de valse avec son amie Annie (voir illustration 23); Alistair, qui l'a reconnue, l'invite à danser mais Eliza lui rappelle immédiatement que "ça ne se fait pas de danser entre garçons ». Cette dernière est d'ailleurs sous le charme du mystérieux jeune homme dont elle ignore l'identité. Candy quitte ensuite le bal afin de revêtir son costume de Juliette.

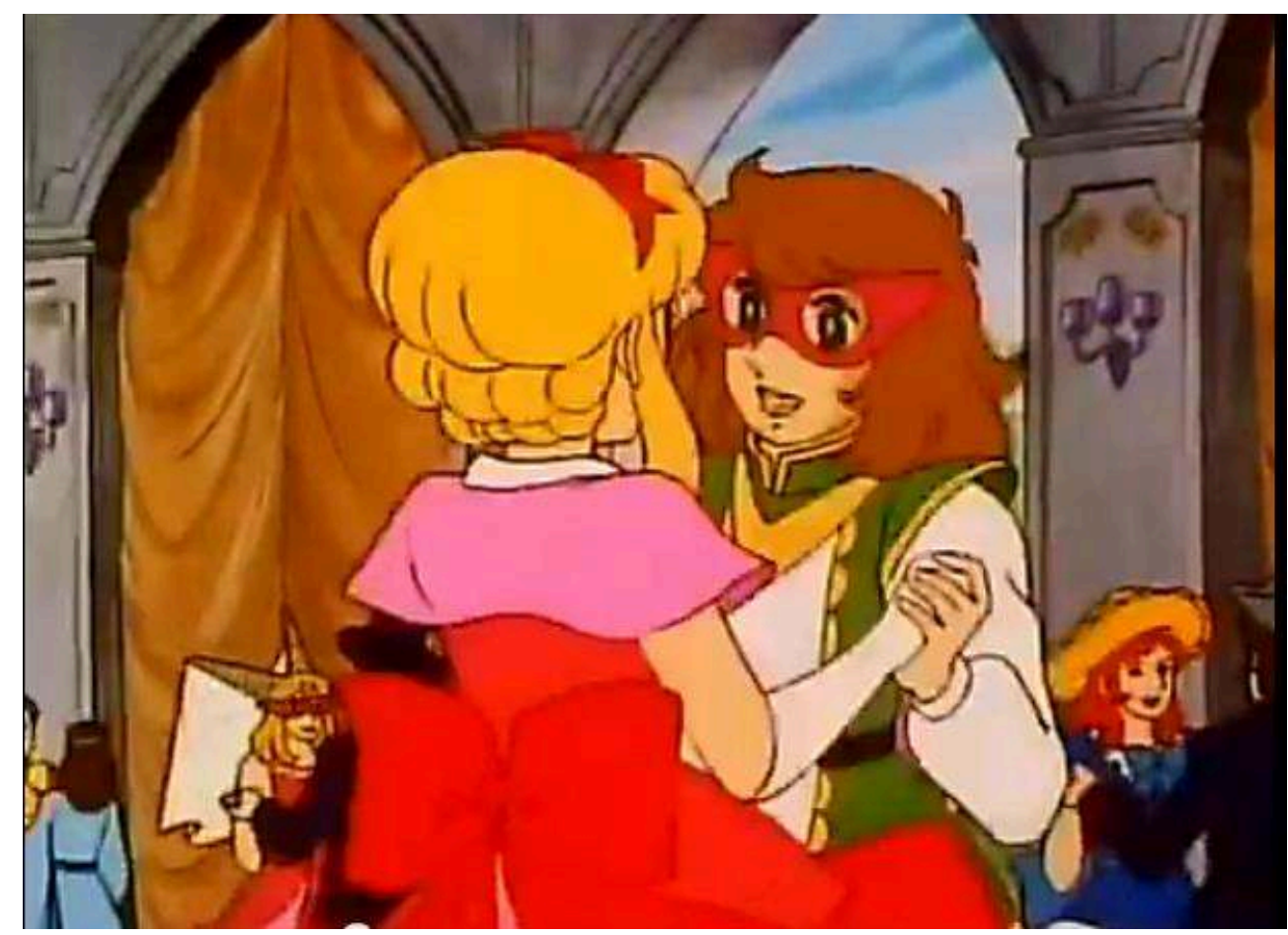

Illustration 23 : Candy déguisée en Roméo danse la valse avec son amie Annie, capture d'écran de l'épisode 41.

Archive personnelle.

TOEl Animation Co., Ltd. Tous droits réservés. 


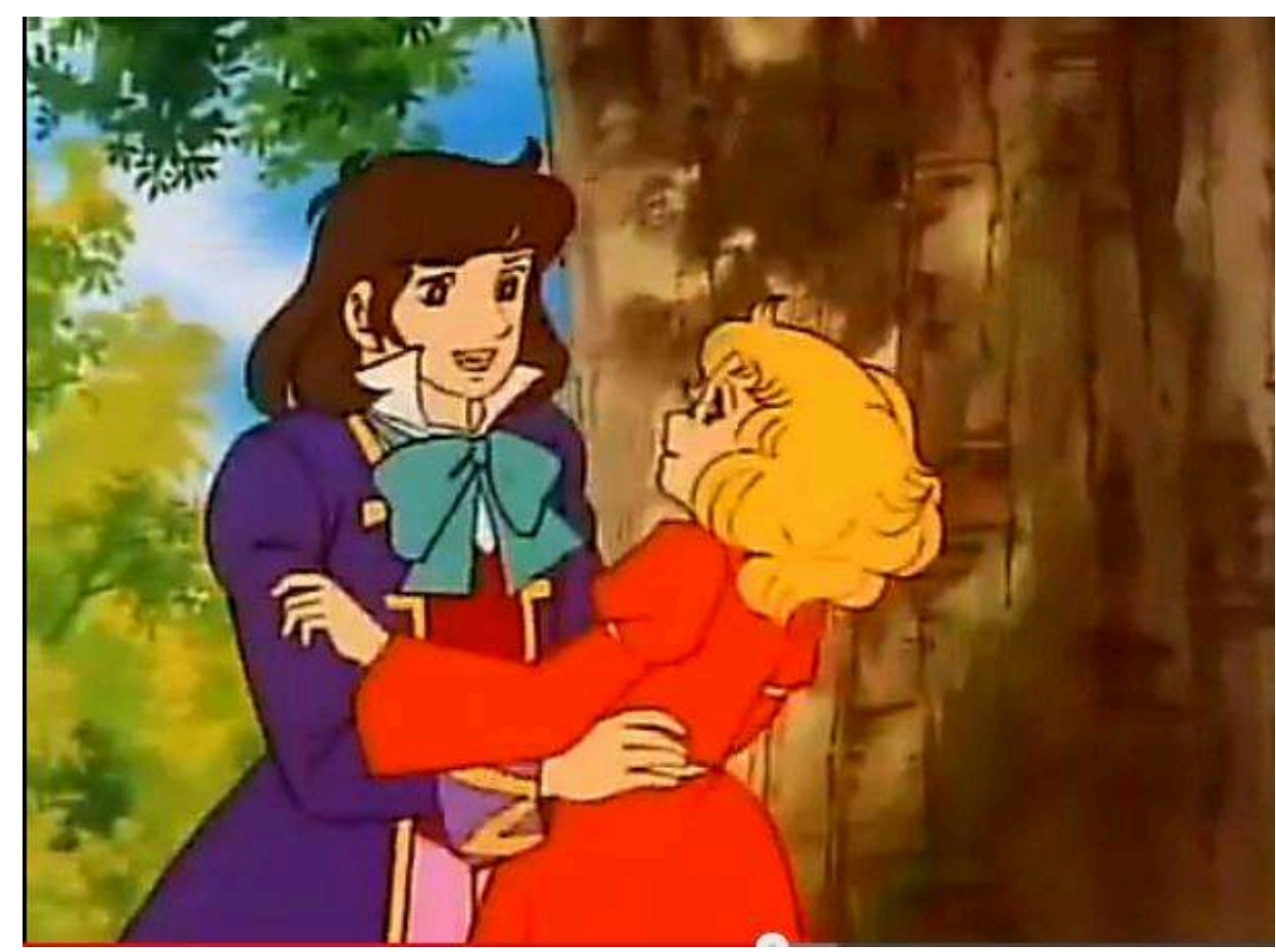

Illustration 24 : Candy déguisée en Juliette danse la valse avec Terry, capture d'écran de l'épisode 41.

Archive personnelle.

TOEl Animation Co., Ltd. Tous droits réservés.

Cette évocation de Shakespeare engage un double brouillage : entre les genres - Candy est à la fois Roméo et Juliette - mais également entre plusieurs pièces de Shakespeare, l'épisode évoquant aussi bien le bal masqué de Roméo et Juliette que les jeux de travestissement de Comme il vous plaira ou de La Nuit des rois. Cette fluidité des identités genrées est néanmoins de courte durée. Après s'être changée en Juliette derrière un fourré, elle découvre Terry, qui est déguisé en Roméo, perché dans un arbre. Il l'invite à danser la valse dans le parc, loin des regards des autres élèves (voir illustration 24). Chacun retrouve ainsi une apparence genrée qui correspond à son sexe, mais aussi le rôle shakespearien auquel il/elle est censé s'identifier : Roméo pour Terry, Juliette pour Candy. Comme Alistair le signale d'ailleurs à Candy : «J'avoue que tu es mieux avec une robe ${ }^{17}$. La subversion des comportements genrés par Candy et sa performativité sont donc de courte durée : les écarts qui se manifestent dans cet épisode entre sexe, genre et désir retrouvent à la fin de l'épisode une cohérence hétéronormée et se manifestent sous la forme d'un "genre intelligible», pour reprendre la terminologie de Judith Butler ${ }^{18}$.

Ces formes transitoires de renversement du genre se retrouvent tout particulièrement autour de la scène du balcon de Roméo et Juliette, dont les multiples avatars disséminés au fil des épisodes constituent un motif récurrent. Candy tient le rôle de Roméo quand elle parvient à pénétrer dans la chambre de Terry au collège de Saint Paul en sautant sur son balcon depuis la branche d'un arbre (épisode 38, voir illustration 25), quand elle se languit sous la fenêtre du jeune homme au cours de l'été passé en Écosse (épisode 43, voir illustration 26) ou quand elle court après le train d'où Terry, accroché à la 
rambarde, l'aperçoit un bref instant (épisode 80, voir illustration 27). La situation est inversée lorsque Terry, qui a invité Candy à la première de Roméo et Juliette, pense à son amour pour la jeune fille sous les fenêtres de l'hôtel où elle séjourne (voir illustration 28).

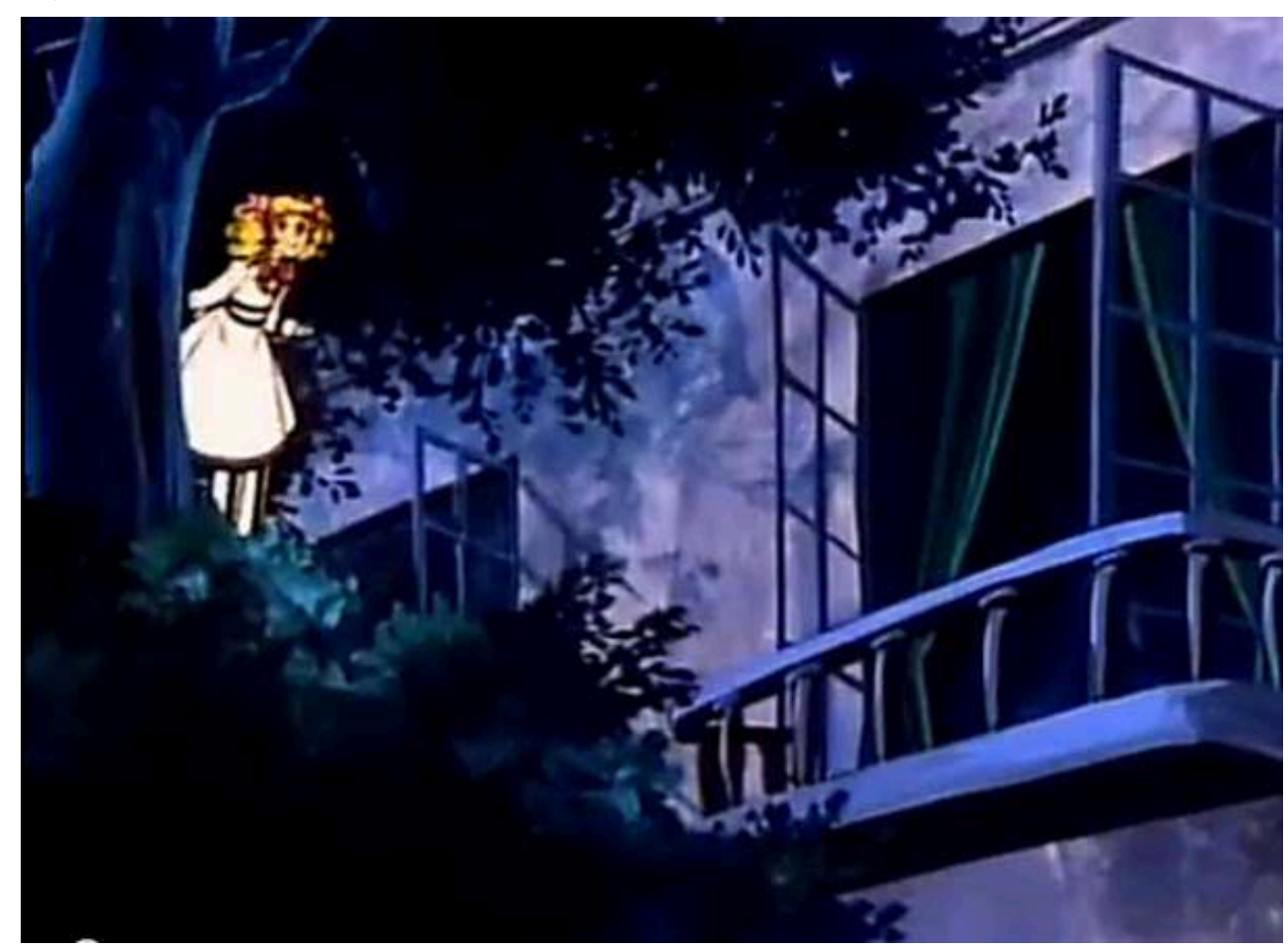

Illustration 25 : Candy devant le balcon de Terry au collège de Saint Paul, capture d'écran de l'épisode 38.

Archive personnelle.

TOEI Animation Co., Ltd. Tous droits réservés.

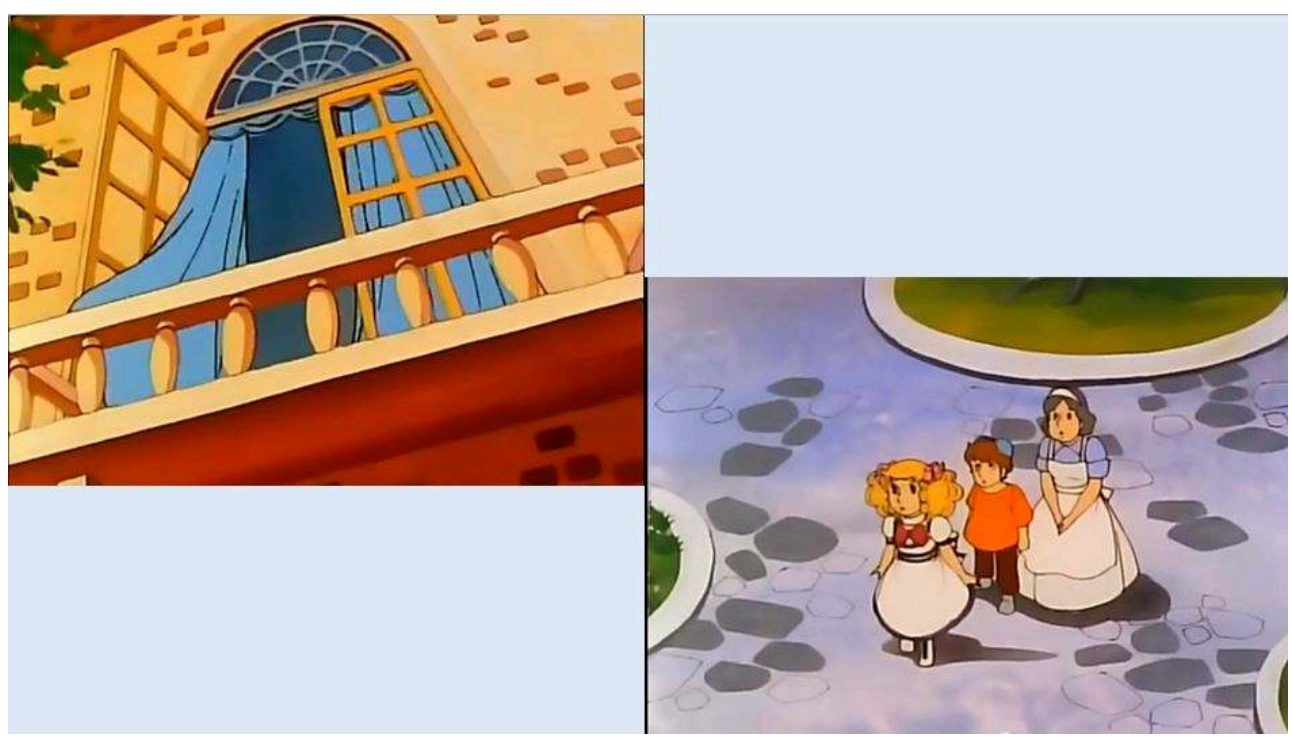

Illustration 26 : Candy sous les fenêtres de Terry en Écosse, captures d'écran de l'épisode 43.

Archive personnelle.

TOEI Animation Co., Ltd. Tous droits réservés. 


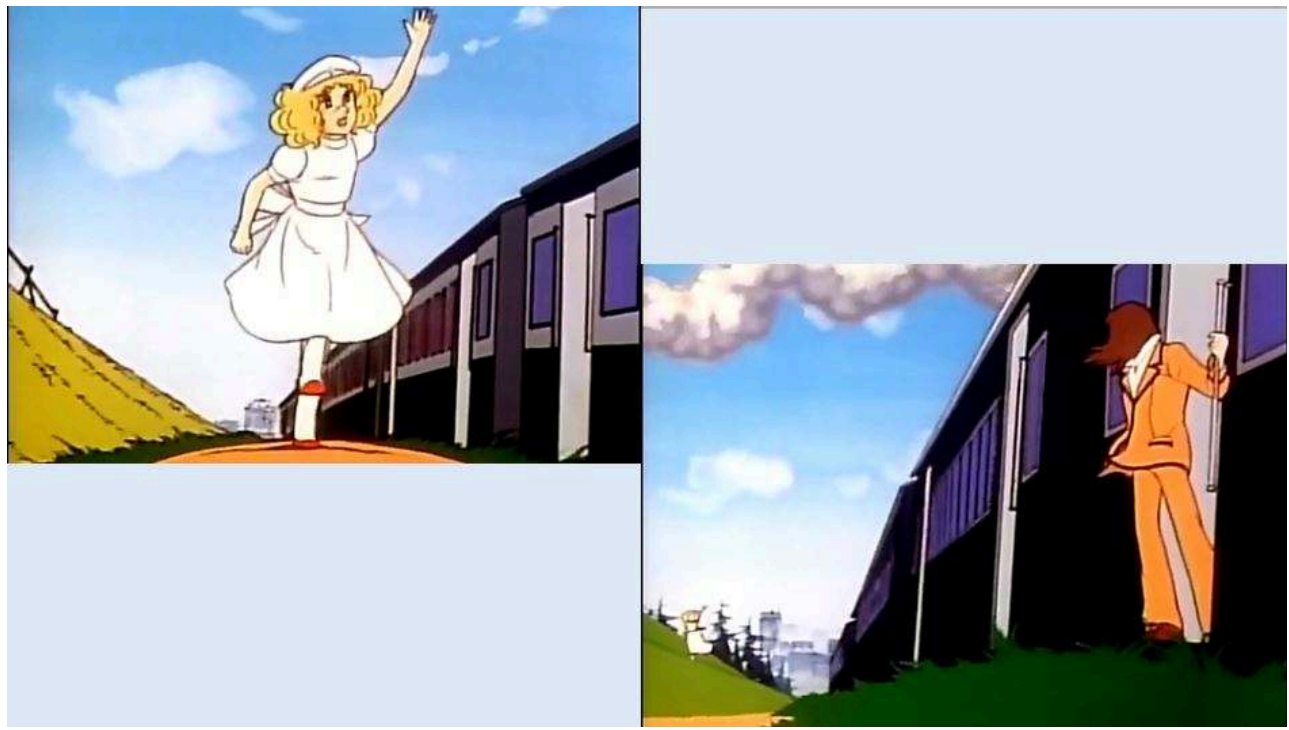

Illustration 27 : Terry se tenant à la rambarde du train après lequel court Candy, captures d'écran de l'épisode 80.

Archive personnelle.

TOEI Animation Co., Ltd. Tous droits réservés.

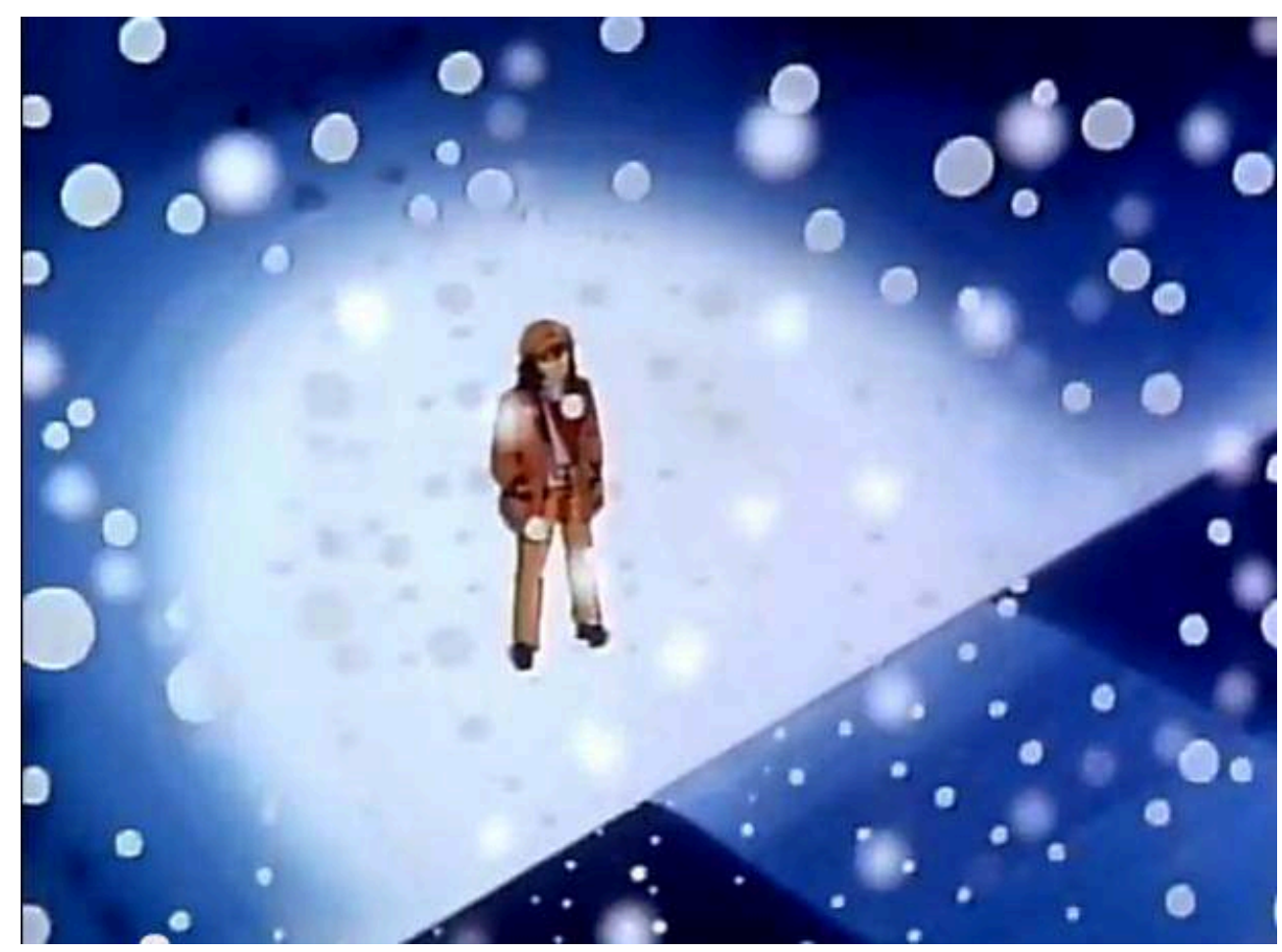

Illustration 28 : Terry sous les fenêtres de Candy à New York, capture d'écran de l'épisode 98.

Archive personnelle.

TOEI Animation Co., Ltd. Tous droits réservés.

La scène est également jouée par Terry en répétition et lors de la première, mais même sur les planches, le brouillage entre le théâtre et la vie demeure, Candy occupant constamment les pensées du jeune homme lorsqu'il déclame ses vers. L'histoire 
d'amour de Candy et Terry semble ne pouvoir dépasser la scène du balcon, qu'ils rejouent sans cesse dans un jeu de variations où l'intrigue ne parvient pas à avancer, fixée dans un fantasme amoureux qui évacue les énergies les plus destructrices de la pièce - notamment la violence mortifère du désir qu'éprouve Juliette pour Roméo. Il est d'ailleurs significatif que Candy, spectatrice de Roméo et Juliette, quitte la représentation à l'entracte - un spectacle avorté à l'image de la relation impossible entre les deux personnages ${ }^{19}$.

L'anime transforme ainsi le couple tragique de Roméo et Juliette en trio maudit - Candy, Terry, Suzanne - et ce bien qu'aucun des trois personnages ne passe de vie à trépas. Cependant, les signes sont trompeurs et l'influence de la scène n'est pas là où on l'attend. Quand Suzanne Marlowe apprend qu'elle jouera Juliette et que Terry lui donnera la réplique, elle s'imagine avec bonheur qu'elle va pouvoir vivre son amour à la ville comme à la scène. De même, lorsque Candy entend le «vieux dicton » selon lequel «l'acteur et l'actrice qui jouent ensemble Roméo et Juliette finissent par se marier » (épisode 95), elle ne peut s'empêcher d'avoir peur mais veut garder confiance en Terry.

Or, le feuilleton va contrecarrer le traditionnel «film en miroir " shakespearien ${ }^{20}$, où les intrigues en coulisses sont censées imiter la scène (comme dans Kiss Me Kate, réalisé par George Sidney en 1953, ou Shakespeare In Love, réalisé par John Madden en 1998). Terry a voulu le rôle de Roméo non pas pour séduire Suzanne mais pour faire venir Candy à New York et la rendre fière de lui. Même si Terry et Suzanne finissent effectivement ensemble, Terry et Candy sont toujours présentés comme les " véritables » Roméo et Juliette, les amoureux que le sort s'acharne à séparer.

Cette tangente prise par le feuilleton par rapport aux films en miroir traditionnels se cristallise dans les épisodes 91 et 92 . Dans un théâtre encore vide, Terry répète son rôle de Roméo : «Oh, Juliette, tu es mon Orient, mon soleil, l'astre de mes jours. Oh, les mots me manquent pour te dire à quel point tu es chère à mon âme... ». Mécontent de son jeu, il s'interrompt pour penser non pas à celle qui sera sur scène avec lui, mais à celle qui sera dans la salle à le regarder : « Il faudra que je porte la voix pour que Candy sente que c'est à elle que je m'adresse ». Suzanne rejoint alors Terry sur scène, le prie de ne pas inviter Candy à la première et lui avoue qu'elle l'aime. De surprise, le jeune homme lâche le texte qu'il tenait à la main, comme si la vie tentait (vainement) de prendre le relais de la pièce.

Suzanne se présente comme un personnage à qui l'on vole le rôle qu'elle rêvait de tenir une fois le rideau tombé et que les fictions lui accordent généralement. Elle l'avoue ellemême: «Et quand tu as obtenu le rôle du roi de France dans Le Roi Lear, j'ai été transportée de joie. Je sentais au fond de moi-même que tes paroles ne s'adressaient pas à l'actrice mais à ma propre personne et j'étais inondée de bonheur ». Or, c'est au moment de cette déclaration d'amour, émise par la «Juliette» officielle, que Terry pense à son amour fou et éternel pour une autre Juliette, plus officieuse, celle qui s'était déguisée lors du festival de mai. C'est d'ailleurs en mentionnant ce moment que Terry invite Candy à le rejoindre à New York: "J'aimerais tellement revoir la petite Juliette du collège Royal de Saint Paul " (épisode 96). Les auteurs du feuilleton ont conscience des codes auxquels ils contreviennent et ce n'est pas un hasard si Candy, en voyant l'affiche de Roméo et Juliette chez Terry, a une idée - remplacer le nom de l'actrice par le sien : «Comme ça, eh bien c'est moi qui serai Juliette - au moins sur l'affiche » (épisode 97). Elle fait écho aux spectateurs de la pièce qui entretiennent le mythe d'une 
adéquation parfaite entre la vie et la scène et regrettent l'absence d'une Suzanne Marlowe blessée car « elle aurait peut-être été une meilleure [Juliette], je veux dire plus authentique, elle y aurait mis toute son âme, puisqu'elle est, dit-on, amoureuse de Terrence" - comme si, pour être excellente, une représentation théâtrale devait toujours refléter ce qui se passe à la ville.

Estropiée, sachant qu'elle ne pourra plus remonter sur scène et ne voulant pas être un poids pour Terry, Suzanne fait une tentative de suicide. Elle souhaite se jeter du toit de l'hôpital (ce qui donne lieu à une nouvelle vision détournée d'une Juliette à son balcon dans une tonalité fortement mélodramatique) pendant qu'au théâtre se joue la scène finale où les deux amants se suicident l'un après l'autre. Le montage alterne entre le toit de l'hôpital sous une tempête de neige, le théâtre où résonne la dernière scène de Roméo et Juliette (avec Terry et Karine Kliss dans les rôles-titres) et une version rêvée de cette même scène où Suzanne s'imagine jouer Juliette, rôle qu'elle aurait dû interpréter et qu'elle s'apprête à imiter en se tuant (voir extrait 10).

Extrait 10 : Tentative de suicide de Suzanne, épisode 99.

Archive personnelle.

TOEl Animation Co., Ltd. Tous droits réservés.

Candy arrive juste à temps pour arrêter le geste de Suzanne. Elle interrompt le cours de la tragédie mais, devant la force des sentiments de sa rivale, choisit de sacrifier son propre amour et de se retirer. Terry reste, par devoir, auprès de Suzanne. L'excès émotionnel du mélodrame se reflète dans la tempête de neige comme si les intempéries du Roi Lear, que l'on n'avait pas vues lors de la représentation de l'épisode 79, resurgissaient ici avec force (voir illustration 29).

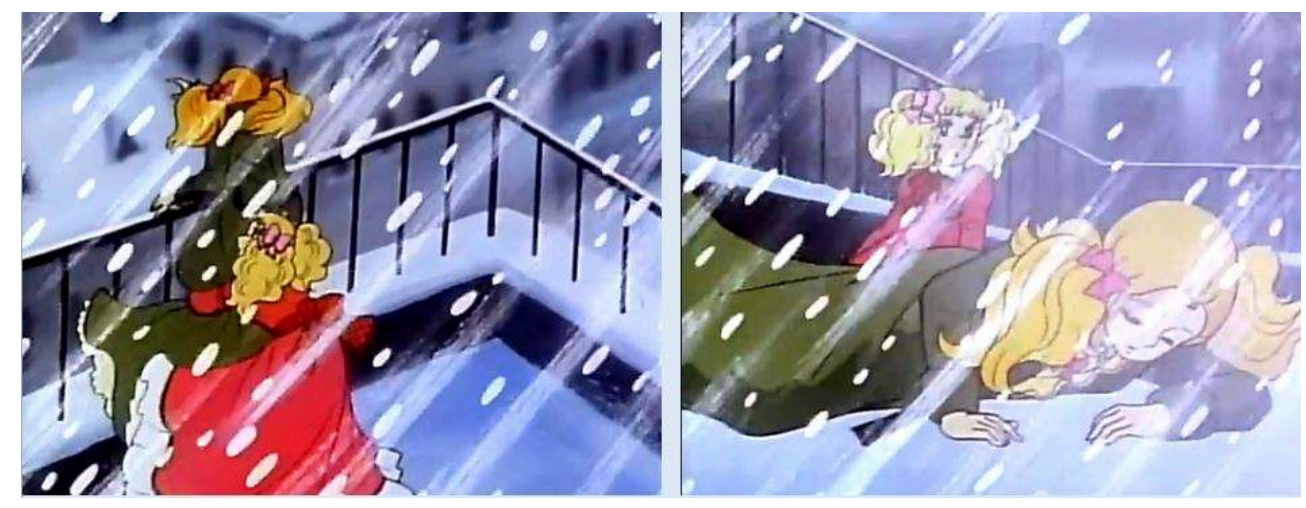

Illustration 29 : Tempête et mélodrame dans Candy, capture d'écran de l'épisode 99.

Archive personnelle.

TOEl Animation Co., Ltd. Tous droits réservés.

Désespéré d'avoir dû renoncer à Candy, Terry part à la dérive. Il finit ivre dans un bar où il déclame à la cantonade la dernière tirade que Roméo adresse au corps inerte de Juliette (épisode 112, voir extrait 11). Ce n'est qu'après avoir vu en catimini Candy travailler comme infirmière auprès d'enfants défavorisés qu'il décide de retourner à New York et de remonter sur les planches. À nouveau, les métiers d'infirmière et de comédien sont mis en parallèle : si l'un soigne le corps, l'autre soigne l'âme. À travers 
un nouvel article intitulé «Le retour du jeune espoir de la compagnie Strasford, Terrence Grandchester », Candy apprend que Shakespeare a finalement sauvé Terry.

Extrait 11 : Terry, d'abord à la dérive, est sauvé par son rêve d'acteur, épisode 112.

Archive personnelle.

TOEI Animation Co., Ltd. Tous droits réservés.

Dans l'épisode 90, Terry est montré devant l'affiche de la production théâtrale dans laquelle il joue, mettant en abyme le médium du dessin animé. À la fin de l'épisode 93, Candy regarde l'une de ces affiches, que son amie Patty lui a rapportée de Pittsburgh. En l'absence de l'homme qu'elle aime, l'image agit comme un substitut du corps de Terry (extrait 12).

Extrait 12

Extrait 12 : L'affiche de Terry qui s'anime, épisode 93.

Archive personnelle.

TOEI Animation Co., Ltd. Tous droits réservés.

Cette scène est emblématique de l'ambivalence des transactions shakespeariennes à l'œuvre dans le feuilleton. De manière métafictionnelle, l'image de Terry se distingue du cadre, semble se détacher du mur et prendre vie, reflétant la manière dont le dessin anime littéralement les pièces de Shakespeare. Cette image qui s'émancipe du médium annonce les nombreuses créations transfictionnelles que les fans réaliseront autour de Candy et Shakespeare. Ils ont imaginé des posters d'autres productions théâtrales comme Hamlet et posté des vidéos sur YouTube où les images de l'anime ou du manga original sont irriguées par la musique du Roméo et Juliette de Franco Zeffirelli $(1968)^{21}$ ou de celle du film Romeo + Juliette de Baz Luhrmann (1996) ${ }^{22}$; d'autres ont également détourné l'affiche de Shakespeare In Love où Terry et Candy prennent symboliquement la place des deux héros du film (voir illustration 30$)^{23}$. 


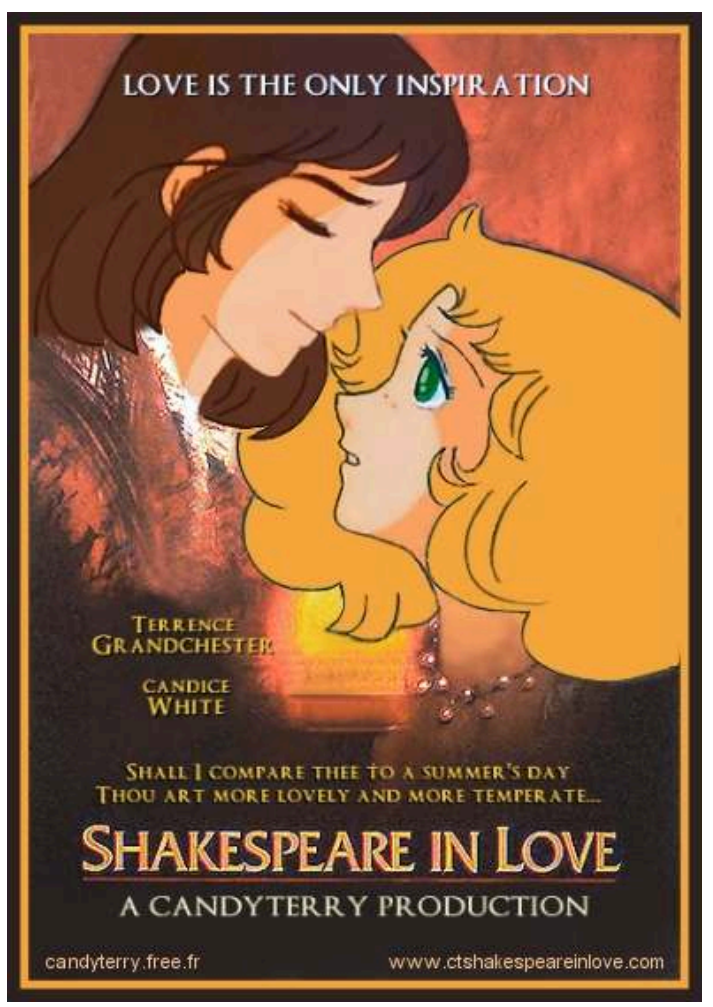

Illustration 30 : Affiche détournée du film Shakespeare In Love (réal. John Madden, 1998).

Archive personnelle.

TOEI Animation Co., Ltd. Tous droits réservés.

Dans ce dernier exemple, le désir des fans d'unir le couple à la fois sur scène et dans la vie rejoint le rêve de Candy devant l'affiche de Terry. L'acteur acquiert une présence spectrale et déréalisée tandis que l'imagination de Candy fait disparaître Suzanne dans l'espoir de la remplacer. Cette vision brouille une fois de plus le théâtre et la vie à travers l'identification aux personnages de la pièce. Mais cette identification est problématique. Candy se rêve en Juliette parce qu'elle pense que la pièce peut avoir une heureuse conclusion, mais également parce qu'elle sur-imprime un roman personnel, non tragique, sur l'œuvre de Shakespeare. Or, depuis la triste fin de Sybil dans Le Portrait de Dorian Gray, on sait les dangers d'une telle lecture de la tragédie. Dans Candy, le théâtre shakespearien est source à la fois de souffrance et de résilience. Même si l'histoire de Candy et Terry reste celle d'un amour impossible, personne ne se suicide. Contrairement à Roméo et Juliette, l'anime affirme que l'amour, même malheureux, ne doit pas mener à la mort. Après avoir assisté à la chute de cheval mortelle d'Anthony, Candy est d'abord inconsolable mais ne le rejoint pas dans la mort ${ }^{24}$. Pour lui faire oublier Anthony, Terry l'oblige à remonter à cheval pour une course enivrante (voir extrait 13).

Extrait 13

Extrait 13 : Terry et son discours sur l'élan vital, épisode 44.

Archive personnelle.

TOEI Animation Co., Ltd. Tous droits réservés. 
C'est précisément dans le premier épisode de l'anime où Shakespeare est cité (épisode 44) que le jeune homme livre un discours rappelant qu'il faut profiter du moment présent : «Nous, nous sommes là, Candy. [...] La vie est la plus forte et les souvenirs doivent toujours laisser la place à la réalité, et la réalité, c'est toi et $\mathrm{moi}^{25}$ ». Face à la disparition des êtres chers, Terry, l'enfant terrible du théâtre shakespearien, affirme, devant les jeunes spectateurs, la puissance de l'élan vital et sa beauté. Si les tragédies existent, elles doivent être surmontées. C'est toujours la survie qui prend le pas - survie à travers le don de soi ou un autre amour.

\section{NOTES}

1. Les analyses de cet article porteront sur la version française doublée par Amélie Morin (Candy) et Thierry Bourdon (Terry).

2. Shakespeare: The Animated Tales est une série de téléfilms animés (d'une demi-heure chacun) adaptant douze pièces de Shakespeare (BBC, 1992-1994).

3. Pour écouter le générique de Candy en français: https://www.youtube.com/watch? $\mathrm{v}=\mathrm{wVcXDbRJ79w}$ (consulté le 2 février 2016).

4. Voir, sur ce point, Barbara Hodgdon, The Shakespeare Trade: Performances and Appropriations, Philadelphie, University of Pennsylvania Press, 1998 ; Alan Sinfield, Faultlines: Cultural Materialism and the Politics of Dissident Reading, Oxford, Oxford University Press, 1992.

5. Comme le rappelle Douglas M. Lanier, la culture populaire peut associer Shakespeare à une certaine britannicité pour apporter un vernis culturel et artistique à une production : « quality craftsmanship, gravitas, trustworthiness, Britishness, antiquity, cultural sophistication, intellectuality, and artsiness " (Shakespeare and Modern Popular Culture, Oxford, Oxford University Press, 2002, p. 112).

6. Sur l'américanisation (et le décentrement) de Shakespeare par la culture populaire, voir Richard Burt, Unspeakable ShaXXXespeares: Queer Theory and American Kiddie Culture, New York, St. Martin's, 1998 ; Denise Albanese, Extramural Shakespeare, Basingstoke, Palgrave Macmillan, 2010.

7. Les paysages dans lesquels Candy grandit ainsi que les tableaux qui ornent les demeures notamment celle de la mère de Terry - entretiennent une ressemblance indéniable avec l'esthétique de la Hudson River School, et plus particulièrement l'œuvre de Thomas Cole et d'Edwin Church (il est significatif que les paysages écossais évoquent eux aussi ces œuvres américaines ou la peinture romantique européenne). Ces espaces idéalisés, où les personnages vivent en parfaite harmonie avec un environnement pourtant menacé par la domestication progressive du territoire américain, sont associés aux valeurs qui fondent l'ethos américain dominant du XIX ${ }^{\mathrm{e}} \mathrm{du}$ siècle contre une tradition aristocrate étroitement assimilée par les Démocrates de l'époque à la culture de l'Ancien Monde: indépendance (self-reliance), mobilité sociale, ruralité, effort individuel (industry), vertu et piété.

8. John Hector St John de Crèvecœur, Letters from an American Farmer, éd. Susan Manning, Oxford, New York, Oxford University Press, 1998, Letter 3, p. 40-82.

9. Voir Roger Manvell, Ellen Terry, Londres, Heron Books, 1968, p. 129; Sheridan Morley, John Gielgud: The Authorized Biography, New York, Simon \& Schuster, 2002, p. 30.

10. Bravant la mère supérieure du collège, Terry lui déclare ainsi : "À les voir vous leur donneriez le Bon Dieu sans confession, mais si vous pouviez lire dans leurs pensées, vous 
deviendriez toute rouge [...]. Toi, viens me prévenir quand la représentation sera terminée. Et maintenant salut les enfants de chœur, amusez-vous bien ».

11. Le décor de la scène où le jeune Siward est tué évoque, quant à lui, l'adaptation filmique de Macbeth par Orson Welles (1948).

12. Nous remercions Pierre Berthomieu pour ce précieux détail.

13. Le livre s'ouvre d'ailleurs à la japonaise et se lit de droite à gauche, trahissant ainsi l'origine de l'anime.

14. William Rounseville Alger, Life of Edwin Forrest, the American Tragedian, 2 vol., Londres, Philadelphie, J. B. Lippincott \& Co, 1877, p. 739-790.

15. La voix de l'acteur qui double Hattaway/Lear est celle de Daniel Gall qui était connue par les jeunes spectateurs de l'époque comme celle qui doublait aussi le vaillant Actarus, prince d'Euphor, dans l'anime Goldorak. Lear bénéficie donc d'un intertexte qui lui confère une autorité bienveillante.

16. L'anime reprend, dans cet épisode, les codes des contes de fée : Candy perd sa chaussure telle une nouvelle Cendrillon et laisse derrière elle un mouchoir que Terry finira par récupérer.

17. À la fin de l'épisode, c'est au tour de Terry de transgresser les frontières du genre : afin d'éviter que l'escapade de Candy ne soit découverte par les sœurs du collège, il entre par la fenêtre dans la chambre que Candy n'aurait pas dû quitter et se glisse sous les draps de la jeune fille. Il devient "Candy » l'espace d'un instant, mais en recouvrant intégralement son corps et son visage.

18. Judith Butler, Trouble dans le genre. Le féminisme et la subversion de l'identité, trad. Cynthia Kraux, Paris, La Découverte, 2006 (1990), p. 84.

19. Les fabricants japonais de jouets et poupées autour de Candy n'auraient pas été sans influence sur l'éloignement de Terry afin de préserver la pureté de la jeune fille. Voir http:// www.candyneige.com/encyclopedie/curiosites/curiosites/

curiosites.htm\#Le\%20merchandising\%20a-t-

il\%20influenc\%C3\%A9\%20la\%20disparition\%20de\%20Terry\%20apr\%C3\%A8s\%20le\%20coll\%C3\%A8ge\%20SaintPaul\%20? (consulté le 2 février 2016).

20. Voir Kenneth S. Rothwell, A History of Shakespeare on Screen: A Century of Film and Television, Cambridge, Cambridge University Press, 1999, p. 219 ; Cary M. Mazer, Cary M., « Sense/Memory/ Sense-memory: Reading Narratives of Shakespearian Rehearsals », Shakespeare Survey n62, 2009, 328-348.

21. http://www.youtube.com/watch?v=oZL8PSGC_2o ou http://www.youtube.com/watch? $\mathrm{v}=\mathrm{WgX} \_\mathrm{X} 92 \mathrm{WOB} 8$ (vidéos consultées le 2 février 2016).

22. http://www.youtube.com/watch?v=7IF_iTarp4w (consulté le 2 février 2016).

23. Voir les nombreux exemples de détournement d'affiches ici: http://candyterry.com/ TGgallery/tgromancecredits3.html (consulté le 2 février 2016).

24. Il est à noter que le doublage français édulcore l'anime japonais : pour protéger la sensibilité des jeunes spectateurs français, les dialogues laissent entendre qu'Anthony n'est pas mort mais est grièvement blessé, ce qui crée bien sûr des problèmes de continuité et de logique narratives.

25. Entendue de manière rétrospective, cette réplique est aussi porteuse d'une ironie cruelle puisque le couple de Terry et Candy restera toujours de l'ordre de la fiction. 


\section{RÉSUMÉS}

Candy, manga japonais en neuf volumes de Yumiko Igarashi (dessinatrice) et Kyoko Mizuki (scénariste), a été adapté en une série télévisée d'animation (ou anime) pour enfants comprenant 115 épisodes de 26 minutes diffusés entre 1976 et 1979 (à partir de septembre 1978 en France). Alors que les adaptations de Shakespeare à l'écran sont en jachère à cette période, Candy a fait découvrir son œuvre à toute une génération d'enfants nés dans les années 70 en leur donnant l'occasion d'assister à des scènes tirées de Macbeth, du Roi Lear et de Roméo et Juliette. Bien que l'anime n'échappe pas aux clichés et aux facilités mélodramatiques, cette fiction non anglophone pour la jeunesse tient néanmoins un discours complexe sur les transactions anglo-américaines de Shakespeare. Il s'agira d'explorer les lignes de faille d'un feuilleton qui construit une tension entre un Shakespeare " authentiquement » britannique et un Shakespeare américain populaire, met au jour les mécanismes mêmes de la production théâtrale et interroge sa portée au sein de la société.

Candy Candy, a Japanese nine-volume manga created by Yumiko Igarashi and Kyoko Mizuki, was adapted into a children's anime television series comprising 115 26-minute episodes which were broadcast between 1976 and 1979 (and from September 1978 in France). Whereas hardly any screen adaptations of Shakespeare were released at the time, Candy Candy gave an opportunity to a whole generation of children born in the 1970s to discover the playwright's works through scenes taken from Macbeth, King Lear and Romeo and Juliet. If the anime does not avoid melodramatic clichés, this non-Anglophone work offers nonetheless a complex vision of AngloAmerican Shakespearean transactions. This article aims at exploring the faultines of a serial fiction which dramatizes a tension between a "truly" British Shakespeare and a popular American Shakespeare, unveiling the mechanisms of theatrical production and questioning its social impact.

\section{INDEX}

Keywords : appropriation, Candy, cultural transactions, England, manga, United States of America

Mots-clés : Angleterre, appropriation, Candy, États-Unis, manga, transactions culturelles

\section{AUTEURS}

\section{SARAH HATCHUEL}

Université du Havre, EA 4314, GRIC

RONAN LUDOT-VLASAK

Université de Lille, EA 4074, CECILLE - Centre d'Études en Civilisations Langues et Lettres Étrangères, F-59000 Lille, France 